\title{
Wisdom or Madness? Comparing Crowds with Expert Evaluation in Funding the Arts
}

\section{Citation}

Mollick, Ethan, and Ramana Nanda. "Wisdom or Madness? Comparing Crowds with Expert Evaluation in Funding the Arts." Management Science 62, no. 6 (June 2016): 1533-1553.

\section{Published Version}

https://pubsonline.informs.org/doi/abs/10.1287/mnsc.2015.2207

\section{Permanent link}

http://nrs.harvard.edu/urn-3:HUL.InstRepos:41273531

\section{Terms of Use}

This article was downloaded from Harvard University's DASH repository, and is made available under the terms and conditions applicable to Open Access Policy Articles, as set forth at http:// nrs.harvard.edu/urn-3:HUL.InstRepos:dash.current.terms-of-use\#OAP

\section{Share Your Story}

The Harvard community has made this article openly available.

Please share how this access benefits you. Submit a story.

Accessibility 

H A R V A R D
B U S I N E S S
S C HOO L

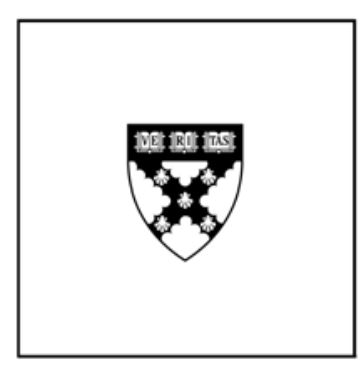

\section{Wisdom or Madness? Comparing Crowds with Expert Evaluation in Funding the Arts}

Ethan Mollick

Ramana Nanda

\section{Working Paper}

14-116

August 26, 2015 


\title{
Wisdom or Madness? Comparing Crowds with Expert Evaluation in Funding the Arts*
}

\author{
Ethan Mollick \\ The Wharton School University of Pennsylvania \\ Ramana Nanda \\ Harvard Business School
}

March 5, 2015

\begin{abstract}
In fields as diverse as technology entrepreneurship and the arts, crowds of interested stakeholders are increasingly responsible for deciding which innovations to fund, a privilege that was previously reserved for a few experts, such as venture capitalists and grant-making bodies. Little is known about the degree to which the crowd differs from experts in judging which ideas to fund, and, indeed, whether the crowd is even rational in making funding decisions. Drawing on a panel of national experts and comprehensive data from the largest crowdfunding site, we examine funding decisions for proposed theater projects, a category where expert and crowd preferences might be expected to differ greatly. We instead find significant agreement between the funding decisions of crowds and experts. Where crowds and experts disagree, it is far more likely to be a case where the crowd is willing to fund projects that experts may not. Examining the outcomes of these projects, we find no quantitative or qualitative differences between projects funded by the crowd alone, and those that were selected by both the crowd and experts. Our findings suggest that crowdfunding can play an important role in complementing expert decisions, particularly in sectors where the crowds are end users, by allowing projects the option to receive multiple evaluations and thereby lowering the incidence of "false negatives."
\end{abstract}

*emollick@wharton.upenn.edu and RNanda@hbs.edu Authorship is alphabetical; both authors contributed equally in developing this paper. We are grateful to Xiang Ao, Ajay Agrawal, Teresa Amabile, Ronnie Chatterji, Jing Chen, Chuck Eesley, Avi Goldfarb, Brent Goldfarb, Mukti Khaire, Josh Lerner, Matt Marx, Matthew Rhodes-Kropf, Antoinette Schoar and Tavneet Suri for helpful conversations and feedback, and to the participants of the Economics of Entrepreneurship and Innovation Conference at Queens School of Business. We thank John Galvin and Andrew Marder at HBS for their help in implementing the survey. We would also like to thank the editors and our three anonymous reviewers for their very helpful comments. Support was provided by the Kauffman Foundation's Junior Faculty Fellowship and Harvard Business School's Division of Research and Faculty Development for financial support. 


\section{Introduction}

One of the central insights of Schumpeter (1942) was to highlight the distinct roles played by entrepreneurs and investors in bringing new ideas to fruition, since it allowed for the possibility that good ideas might be precluded from the market because they were unable to attract financing from investors. Other scholars have shown that the opinions of funding authorities similarly affect the direction of innovation in other critical fields, including scientific research (Bourdieu, 1975; Goldfarb, 2008; Nelson, 1959) and creative industries (Caves, 2000, 2003). In each setting, scholars have noted that constrained financing environments and the control exerted by a small group of experts means that projects that are ultimately funded are not necessarily "objectively best" but are subject to the specific information, agency, and organizational constraints faced by the small number of experts making funding decisions. (e.g. Caves, 2000; Ferrary \& Granovetter, 2009; Goldfarb, 2008; Kerr, Nanda, \& Rhodes-Kropf, 2013; Kortum \& Lerner, 2000).

Rapid technological advances over the past few years have made it significantly easier for innovators to circumvent experts, and instead communicate directly with a large number of interested stakeholders, leading to the growing reliance on "crowds" to make decisions that once rested solely in the hands of a small number experts. For example, the crowdfunding platform Kickstarter has raised more than $\$ 1$ billion for over 60,000 projects from over six million backers since its founding in 2009 , projects that may otherwise have needed to seek funding from venture investors or grant-making bodies. In fact, since 2012, this platform alone raises more money for the arts annually than the total funding provided through the US government-run National Endowment for the Arts. The importance of crowd-based decisions are growing in a wide range of fields, including the funding of technology-based startups (Agrawal, Catalini, \& Goldfarb, 2013; Mollick, 2014), the development of new products (Afuah \& Tucci, 2012; Poetz \& Schreier, 2012; Von Hippel, 1986) and scientific research (Franzoni \& Sauermann, 2014).

Despite the growing role of crowds in making decisions once left to experts, little is known about how crowds and experts may differ in their ability to judge projects. Indeed, for crowds, at least, there is even considerable debate over whether their decisions are actually based on rational criteria at all. Two popular books separated by 150 years offer starkly different views of the nature of crowd decisionmaking, with Charles Mackay (1852) warning about the "madness of crowds" while James Surowiecki (2004) more recently extolled the "wisdom of crowds." Studies to date attempting to understand the differences between crowds and experts have focused on prediction tasks or markets, where 
aggregated decisions can be more accurate than individual actions (Budescu \& Chen, 2014; Larrick, Mannes, \& Soll, 2012; Ray, 2006; Tetlock, 2005), or else on cases where organizations can get positive results by reaching out to crowds under carefully controlled circumstances (Bogers, Afuah, \& Bastian, 2010; Terwiesch \& Ulrich, 2009). Crowdfunding, on the other hand, does not have any such controls, and differs from these previous phenomena in many ways: there is no market reward mechanism for correct answers; no clear criteria determining what is being "predicted"; no expert oversight of the crowd decision-making process; and no direct coordination between crowd members. In this case, the crowd can be subject to many group decision-making fallacies, as Isenberg (2012) argued about crowdfunding: "group irrationality is well-documented - crowds are 'wise' only in a very limited set of circumstances. As often as not, crowds bring us tulip crazes, subprime meltdowns, the Kitty Genovese scandal, Salem witch trials, and other tragedies." There is no clear evidence on whether crowds are rational at all, and, if they are, what differences might exist between the judgment of crowds and that of experts.

Thus, we are interested in shedding light on two questions about the judgment of crowds compared to experts. First, we aim to provide the first robust analysis of the degree to which experts would agree with crowdfunding decisions that rely on taste and judgment, rather than prediction, using rich data from the crowdfunding platform Kickstarter. The second related question we seek to understand is whether crowd-based decision making is "mad" (irrational and inconsistent in decision making relative to experts) or "wise" (generally consistent in selecting potentially successful projects).

Several features of our research design aim to address the specific challenges associated with making such a comparison. First, we have complete data on crowdfunding campaigns (that is, the "applications") for all projects, including those that were unsuccessful, so that we are not sampling on success. Second, we focus our study to theater projects, which have a number of appealing features: evaluating them entails both a subjective artistic component and an understanding of the commercial bottom line which provides useful variation for our study. Further, it is possible to develop a somewhat objective sense of the long-run success of the projects using data on ticket sales and critical reviews in the press so that we can also compare the funding decisions with real outcomes. Additionally, theater funding is a one-time event, not subject to the challenges associated with multi-stage financing that might lead crowds to choose different investments from deep-pocked professional investors even if they rated projects the same (Nanda \& Rhodes-Kropf, 2012). Finally, we recruit expert evaluators who have deep expertise judging theater applications for institutions such as the National Endowment for the 
Arts. The projects were rendered in the same format as the Kickstarter campaigns, had similar financial requirements to traditional grant applicants, and were stripped of any references to the outcome of the campaign. We randomly assign "sets" of projects to these experts to evaluate, where each set consists of three failed and three successful projects. This approach allows us to also include expert fixed effects to examine the robustness of our results.

We have three main findings. First, on average, we find a statistically significant congruence between the realized funding decisions by crowds and the evaluation of those same projects by experts. Projects that were funded by the crowds received consistently higher scores from experts, were more likely to be rated as being the best of the six in the set, and were much more likely to have received funding from the experts. This pattern was equally true for projects that were "overfunded" on Kickstarter - that is, projects that raised more money that was asked for. Given the strong positive correlations we observe in crowd and expert evaluations, even in a category with a subjective nature such as theater, this suggests both broad similarities between how experts and crowds judge projects and that crowds are generally consistent in their choices of which projects to back, allowing us to reject the "madness of crowds" in our setting.

Our second finding is that despite the broad congruence in evaluation, we see a systematic pattern in terms of the disagreement. Of the projects where there is no agreement, the crowd is much more likely to have funded a project that the judge did not like than the reverse. Around $75 \%$ of the projects where there is a disagreement are ones where the crowd funded a project but the expert would not have funded it. We also see a clear pattern in terms of the characteristics of projects that are liked by the crowds: they offer multiple tiers of rewards and provide more updates. In fact, projects that were ranked highly by the experts but not funded by crowds had systematically fewer reward levels, fewer pictures and fewer videos. That is, we seem to find that there is an "art" to raising money from crowds, one that may be systematically different from that of raising money from experts. The crowds seem to place emphasis on, or extract information content from different attributes of the process than experts.

Our third finding relates to the longer-term outcomes of these projects. An attractive feature of the fact that most of the disagreements are related to projects funded by the crowd, we are able to compare the long term outcomes of projects that were liked by both crowds and experts and those liked only by the crowds. Despite the fact that these were not rated as highly by the experts, we find no qualitative or quantitative differences in the long-term outcomes of these projects. They are equally 
likely to have delivered on budget, result in organizations that continue to operate, and, although the metrics for success are subjective, we find strong qualitative evidence that many of these shows had both commercial success and received positive critical acclaim in national outlets such as the New York Times.

We should note that these third set of results are more tentative due to the smaller sample size. However, these patterns suggest that the entry that is facilitated by crowdfunding has the potential to lower the incidence of "false negatives," (that is, viable projects that are turned down by funders) by allowing projects the option to receive multiple evaluations and reach out to receptive communities that may not otherwise be represented by experts. Indeed, crowdfunding allows project creators to directly contact potential customers, providing a rich source of data on the potential interest in an artistic endeavor, in addition to any funds raised.

Our results are relevant to the growing interest to management scholars in the role of crowds in addressing traditional organizational functions (Afuah \& Tucci, 2012; Boudreau, Lacetera, \& Lakhani, 2011; Franzoni \& Sauermann, 2014; Greenstein \& Zhu, 2014; Terwiesch \& Ulrich, 2009). Our findings are also related to the role that crowds may play in reducing financing constraints of new ventures. The falling cost of starting new ventures has allowed the possibility of individuals with small amounts of capital to participate in financing such ventures, and our results shed light on the extent to which backers on these platforms may be able to reduce information asymmetries as opposed to becoming victims to information cascades. We address the generalizability of our findings in Section 6.

The rest of the paper is organized as follows. In Section 2 we outline the theoretical predictions associated with studying differences between crowds and experts. Section 3 outlines our methods and provides details on the implementation of the survey. Section 4 describes the data, Section 5 outlines our main findings. Section 6 provides a discussion of the results and Section 7 concludes.

\section{Theory}

Scholars have long noted the great importance of experts, who have historically held a privileged position in many industries, acting as arbiters of taste, quality, and appropriateness (e.g. Caves, 2000; Ginsburgh, 2003; Zuckerman, 1999). Expert judgments are influential in a number of ways, including acting as predictors of commercial success and influencers of popular opinion (Eliashberg \& Shugan, 1997), as well gatekeepers of vital resources (Ginsburgh, 2003; Reinstein \& Snyder, 2005b). As an example of these three forms of influence, consider experts who select which entrepreneurial 
ventures should receive funding: venture capitalists. VCs select firms to fund based on their predictions of future market demand (Baum \& Silverman, 2004; Gompers \& Lerner, 2004; Shane \& Venkataraman, 2003). Further, venture capital investment serves as an influential signal to other players in the market, suggesting a startup is to be taken seriously (Baum \& Silverman, 2004; Hellmann \& Puri, 2002). Finally, venture capitalists serve as gatekeepers to vital resources. As Ferrary and Granovetter (2009) write: "By selecting start-ups, the VC firms implicitly prevent the other agents in the complex network of innovation from collaborating with start-ups that do not get VC funding. It could be argued that potential valuable innovations have never reached customers because they did not get VC funding."

In the arts, where profitability is not always the standard goal of creators, experts play an even more critical role as influencers and gatekeepers. Especially in high culture, expert critics are "sometimes more important than creators," since they determine the governing aesthetics of high culture, as well as which creators receive resources (Gans, 2008). Studies in the film industry, for example, have shown that expert critics are particularly influential to the success of smaller artistic movies (Reinstein \& Snyder, 2005a). Further, experts are often gatekeepers of funding for the arts, playing critical roles in allocating funding from the government, corporate, and foundation sources that make up $24.6 \%$ of all revenues for not-for-profit performing arts groups and museums in the United States (Woronkowicz, Nicols, \& lyengar, 2012). Crowdfunding, however, offers an alternative to the traditional expert control over artistic funding and culture.

Crowdfunding provides a method of funding projects that differs in several aspects from expertrun processes like grant-making or venture capital. First, rather than being in the hands of a small group of individuals, it is democratic - over six million people have funded projects on Kickstarter alone. Second, as opposed to the tightly-knit expert community (Wenger \& Snyder, 2000), crowdfunding backers are loosely organized, if at all. Third, compared to the closed networks of Silicon Valley or the world of theater, in crowdfunding almost all communication between those seeking funding and potential backers occurs in open, online communities. Fourth, crowdfunding in its current form involves no equity or monitoring rights ${ }^{1}$; backers have little to no further influence over organizations they backed, and gain no return other than the potential of enjoying the outcome of a project.

\footnotetext{
${ }^{1}$ The data collected is from a period where crowdfunding where no equity investment is permitted, though the US Congress has authorized equity crowdfunding (JOBS Act, $112^{\text {th }}$ Congress), it has yet to be implemented as of the time of this writing.
} 
The use of crowd judgment in crowdfunding also differs greatly from prior approaches to generating information from large groups. Other attempts to harness the innovative power of large groups - such as crowdsourcing (Poetz \& Schreier, 2012), innovation tournaments (Boudreau, Lacetera, \& Lakhani, 2010; Terwiesch \& Ulrich, 2009), and collective and group innovation (Jeppesen \& Frederiksen, 2006; O'Mahony, 2003) - ultimately have an expert authority overseeing the actions of the crowd. And, unlike prediction markets (M. Chen, 2008; Ray, 2006; Wolfers \& Zitzewitz, 2004), crowdbased approaches do not operate like markets, in that there are not buyers and sellers trading contracts in an efficient manner. Instead, crowd judgment depends on the aggregate actions of many individuals making small contributions to a larger goal, in the place of experts making large-scale resource allocation choices themselves. While the success or failure of a particular project may be influenced by the degree of pledges already made (Kuppuswamy \& Bayus, 2013), backing decisions are individual, not collective. There is no centralized price-setting mechanism, tournament, or selection process that aggregates crowd preferences. Thus, the crowd in crowdfunding consists of a group of mostly uncoordinated amateurs.

Theory provides ambiguous predictions about whether and how crowd evaluations should differ from that of experts. One the one hand, the crowd allows for a wider range of expertise and preferences to be leveraged in group decision-making, suggesting that 'collective wisdom' might make evaluation more accurate, reducing information frictions and providing greater efficiency in financing decisions. For example, studies on forecasting have supported the idea that experts are no more accurate than informed amateurs (Tetlock, 2005), while examination of Wikipedia has shown that it compares favorably on many dimensions to expert-created content (Clauson, Polen, Boulos, \& Dzenowagis, 2008; Giles, 2005; Rajagopalan et al., 2011). Further, recent research on Wikipedia has shown that while there may be political biases in certain articles (Greenstein \& Zhu, 2012), as these articles are more heavily edited by the crowd, they ultimately become less biased than similar work produced by the experts at Encyclopedia Britannica (Greenstein \& Zhu, 2014).

The research on crowds that seeks to explain these findings focuses on the value of combining many opinions, as opposed to relying on the views of individual experts (Larrick \& Soll, 2012). When crowds have diverse sources of information and expertise with a problem area, they can provide more accurate collective forecasting than can even well-informed individuals (Larrick et al., 2012). Indeed, a substantial amount of research has gone into examining the best method of combining the predictions of many individuals as accurately as possible (Budescu \& Chen, 2014; Larrick \& Soll, 2012; Makridakis \& 
Winkler, 1983). While these studies have shed considerable light on how to employ the wisdom of the crowd, the emphasis on assessing crowds based on accuracy assumes that there is an objectively defined "correct answer" that both the crowd and experts are attempting to reach. When selecting startup companies to fund, artistic works to develop, or innovations to pursue, the nature of a correct answer is less clear. In these cases, the key issue is less about selecting a combined prediction and much more about understanding whether there are systematic differences between crowds and experts in the types of projects they seem to prefer, or, indeed, if crowds are at all consistent in how they assess projects.

We may expect several factors to drive some systematic differences in the types of projects that are funded by crowds compared to experts. First, it is not clear that the crowd, as a whole, has the expertise to evaluate projects in the same way as experts (Simmons, Nelson, Galak, \& Frederick, 2011). There are no admissions criteria for entering the crowd, making it unclear how the crowd would develop criteria to identify potentially high quality projects in areas where they do not have expertise. Since crowds are pledging smaller amounts of money per project, they also have less of an incentive to gather information on the project and hence are more likely to be subject to herding driven by information cascades. Such herding can be rational, as outlined by several economics models (Banerjee, 1992; Bikhchandani, Hirshleifer, \& Welch, 1992; Devenow \& Welch, 1996; Scharfstein \& Stein, 1990), where project backers observe the actions of other project backers, and thus view the presence of other backers as a sign of quality. Herding can also be mimetic, as backers simply mimic others, without an underlying rationale (Cipriani \& Guarino, 2005). Crowds may also suffer from a wide variety of factors identified by social psychologists and cognitive scientists that degrade the quality of crowd decisionmaking (e.g. Bahrami et al., 2012; Latane, Williams, Harkins, \& Latané, 1979; Raafat, Chater, \& Frith, 2009). For example, groups can be subject to emotional contagion (Barsade, 2002) and even to hysterical reaction (Balaratnasingam \& Janca, 2006), that may cause crowd members to act in nonrational ways. Crowds could also be fall into patterns of group thinking which bias information processing (Janis, 1982), may overly rely on the work of others (Earley, 1989; Latane et al., 1979), or may deemphasize information that is not shared among group members (Schulz-Hardt, Brodbeck, Mojzisch, Kerschreiter, \& Frey, 2006).

We do not seek to specify which biases may operate under which conditions in crowdfunding, but rather argue that there are many potential reasons why crowds would operate in ways that might be less than wise, especially as crowdfunding does not resemble more controlled opinion-aggregation 
approaches to harnessing crowd wisdom (Budescu \& Chen, 2014; Simmons et al., 2011). Indeed, early studies have found herding in peer-to-peer lending, a form of crowdfunding, with conflicting evidence over the degree to which herding represents positive information cascades or mere imitation (D. Chen \& Lin, 2014; Kuppuswamy \& Bayus, 2013; Zhang \& Liu, 2012). Thus, both prior theory and early empirical results suggest that the crowd could be irrational, subject to many potential biases that would result in inconsistent judgments without clear patterns or decision criteria.

Even in the absence of group biases that subvert rational decision-making, the crowd and experts may differ based on taste or other preferences. The difference in cultural tastes have long been a subject of interest to scholars (Bourdieu, 1984; DiMaggio, 1991; Gans, 2008; Peterson \& Kern, 1996), and the funding decision of experts and crowds would reasonably be expected to reflect differences in high culture and popular culture (Gans, 2008). Even as cultural tastes change among the elite (Peterson \& Kern, 1996), there is still a strong belief that many forms of high culture, serious theater prominent among them (Shrum, 1991), would not be supported by popular culture. Further, the tastes of the critics serves a role beyond selecting artwork, and is part of the process by which elite social classes sustain and replicate themselves (DiMaggio, 1991). Additionally, the difference in tastes between the crowd and experts may not even be based on the underlying quality of the work. Given that some significant proportion of crowdfunding is based on the support of friends and family (Agrawal, Catalini, \& Goldfarb, 2010), it could simply be that the crowd is primarily focused on supporting popular individuals, rather than quality products. These differences in tastes are important, as selection contexts that apply different preferences in funding projects can result in the support of very different forms of art (Wijnberg \& Gemser, 2000) and alter the sorts of ideas that are ultimately funded and pursued throughout the economy. Therefore, even in the absence of group cognitive biases that make decisionmaking inconsistent, crowds may still have a completely different set of tastes then experts, suggesting that moving from expert to crowd-based judgments could radically alter the type and nature of art being funded.

Ultimately, we are left with two potential views of the crowd. In one case, we have a crowd that is fundamentally wise. It may differ on some selection criteria from experts due to taste or the structure in which screening takes place, but would have a consistent set of decisions that have a rational underlying framework. If the crowd is wise, the key question becomes the taste of the crowd compared to experts, and its consequences. A second option is that the crowd is instead more subject to the many potential fallacies of group cognition; is driven by factors unrelated to quality; has radically different 
tastes than experts; and/or is inconsistent in its judgment. Our study aims to shed light on which of these two polar extremes best typifies the nature of crowdfunding we see today, and to explore the differences between expert and crowd judgment.

\section{Research Design}

We chose to work with data from Kickstarter, which is the largest and most prominent crowdfunding platform in the world, having successfully helped raise over $\$ 1$ billion in funding across all applicants in the last five years. Due to the strong network effects that tend to be present in such platforms, working with the largest, most prominent, and successful platform ensures that we are likely to observe a representative set of projects -- including the very best -- that are seeking funding from crowds. A second attractive feature of our setting is that we have access to all the campaigns run by Kickstarter, including those that did not succeed in meeting their funding goals, which allows us to look at the differences in evaluation, without sampling on success.

Since a key goal of our paper is to examine the extent to which experts would agree with the funding decisions of crowds, we focused our analysis on a field where there is an established set of externally-validated experts that could be used to examine the judgment of crowds. We also wanted to focus on an area where projects have both a subjective artistic component and a measure of a commercial bottom line, since the former is a setting where tastes may be expected to differ and the latter is a feature that is particularly relevant for new ventures outside of the arts. Given these two criteria, we decided to focus on theater, where the existing literature suggests a long-standing tension between experts and mass audiences in artistic endeavors (Gans, 2008; Kim \& Jensen, 2011; Wijnberg \& Gemser, 2000) while at the same time embodying many features of projects that have a commercial bottom line. Theater is especially relevant in crowdfunding, because, as mentioned, as of 2012, Kickstarter campaigns became a larger funder of the arts than the expert-run National Endowment of the Arts.

Figure 1 provides an annotated example of a Kickstarter theater project from our sample. As can be seen in the Figure, project creators generate a pitch to convince backers to support their project, using a combination of video, text, and images to communicate their vision for the completed project. As is common in reward-based crowdfunding, backers may receive some sort of reward for a project, such as a ticket or a mention in a program, but do not gain any financial stake in the project or profit from the project in any way. Pitches, project goals, and aspirations of project creators can vary widely 
between projects, and the projects in our sample included revivals of Broadway plays, adaptations of books to the stage, original musicals, works aimed at children, and new dramatic productions.

[Figure 1 about here]

Theater also has the attractive property that it is possible to measure "real outcomes" in a manner that is independent of the funding decision, by learning about the commercial performance or critical reviews of projects following the Kickstarter campaign. Although some of these data are noisy, they help shed some light on whether the real outcomes also correlate with funding decisions. They are also especially useful in addressing whether projects attempt to deliver their promised outcomes.

We restrict our attention to Kickstarter projects that were aiming to raise at least $\$ 10,000$ in funding. The funding goal of at least $\$ 10,000$ focuses on the subset of applicants whose ambitions and goals are more closely aligned with those applying for funding from traditional sources such as the National Endowment for the Arts, as well as several other grant making organizations for theater. To put this in perspective, the NEA made 1,083 grants in the first round of funding for FY 2014, with an average grants size of around $\$ 24,000$. The average funding goal for projects in our sample is $\$ 20,500$, with the largest goal for successful projects being $\$ 75,000$.

For experts, we draw on the experience of 30 judges who have deep and extensive knowledge of theater, as evidenced by their background in evaluating theater applications for national grant making bodies such as the National Endowment for the Arts $^{2}$ ). We asked each of these judges to evaluate 6 projects, 3 of which were successes and 3 of which were failures. We were able to strip out any data on the outcome of the project, but still render the projects, including videos, for the judges in a manner that was equivalent to the display on Kickstarter (including fonts, graphics, typographic errors, etc.) This not only allows us to have a representative set of applications for funding (rather than just evaluating the successful cases), but also allows us to display the applications similar to the way that the crowds viewed them, and hence evaluated them.

Evaluations were conducted using an online survey instrument derived from extensive interviews and testing with individuals who had been involved in judging for the NEA. We identified five

\footnotetext{
2 Judges have served on a mean of 5 panels each for national theater prizes and awards. All judges were also involved in theater, either as critics, artistic directors, dramaturges, theater managers, or in some other role. In addition to the NEA, judges had been part of panels for the Mellon Foundation, the Doris Duke Charitable Trust, and other major theater prizes and grant-making bodies.
} 
key criteria, and asked three questions about each, using a Likert scale from 1 to 5 , with 5 being "Strongly Agree." The five criteria we evaluated were: novelty (example: "This project is original"), feasibility (example: "This project can be implemented with the resources in the proposal"), quality (example: "The proposal for the project is of high quality "), reach (examples: "This project would reach a diverse audience" and "This project would be commercially viable/profitable"), and social relevance (example: “Assuming it was completed as planned, this project would advance a cultural, political, or artistic dialogue"). The Appendix contains the full list of questions as well as details on the survey instrument. Additionally, we showed judges the goal of the Kickstarter project in question, and asked "How much do you think this project should be funded for, in dollars? Answer 0 if you do not think it should be funded. Assume you have enough budget to fully fund all of the projects in the survey." We also asked judges to list the best and worst projects of those that they had seen.

We generated a stratified random sample of theater projects that attempted to raise at least $\$ 10,000$ on the Kickstarter platform between May, 2009 and June 2012. We focused our attention on projects that were raising money for a specific performance, as opposed to efforts such as fundraising for building a new theater. Again, this was to match the types of proposals typically seen in national grant competitions.

There were 257 projects that met our criteria, from which we randomly selected 120 . Specifically, we created 20 "sets" of 6 projects each, where each set was comprised of 3 projects that failed to reach their funding goal, 2 projects that achieved their goal and 1 project that exceeded its funding goal ${ }^{3}$. Hence, our stratified random sample consisted of 60 failed projects (from a total of 141 failed projects), 40 projects that just met their goal (from a total of 85 such projects) and 20 projects that exceeded their goal (from a total of 31 such projects). Each set of 6 projects was then randomly assigned to a judge, who evaluated the six projects on a range of criteria described above.

It is worth pointing out that since projects were randomly assigned to sets, and judges were randomly assigned, our objective was to ensure that once a judge agreed to evaluate the projects, they did a diligent job in their evaluation (rather than to ensure a high 'response rate' in terms of judges agreeing to evaluate our projects as might be a standard concern in other surveys). We incentivized judges with a $\$ 50$ gift certificate for completing the survey, helping us gain the participation of the high

\footnotetext{
${ }^{3}$ We defined exceeding the funding goal as raising over $10 \%$ more than the ideal goal.
} 
quality experts we required for our test. The quality of the responses is measurable in a number of ways. First, we note that there were virtually no missing values in the responses from the judges, so that there is no response bias in our results. ${ }^{4}$ Second, half the sets (that is 60 projects) were randomly assigned to a second judge for evaluation. Using a squared weighting scheme appropriate for subjective scoring (Cohen, 1968), the kappa statistic which measures the inter-rater agreement for these judges was 0.44. The $Z$ statistic was 7.14, strongly rejecting the hypothesis that the scores were generated at random. While the kappa statistic of 0.44 suggests moderate agreement among the judges, it is worth noting that theater projects have an inherent element of subjectivity to them. Given this, we are reassured that there is a strong and consistent signal that seems to emerge from the judges' evaluations of the projects. Also, as will be discussed, we use a variety of methods of measuring the judge's responses to proposed projects, and find the decisions to be robust across these approaches.

Overall, our research design aims to combine the expertise of real judges for traditional grant making bodies with a sample of applications from a crowd funding platform that reduces, if not eliminates, many of the concerns about selection that were outlined above. On a qualitative dimension, feedback from our survey participants suggested that there was reasonable overlap in the types of projects applying for funding through Kickstarter and the types that they had judged for in the past. In addition, many judging bodies, including the National Endowment for the Arts, are moving towards a system where judges have electronic access to applications, in part to be able to view videos that provide much richer information on the application in a short amount of time. This reduces concern that the mode of information dissemination is foreign to the judges although we cannot rule out that specific projects were presented in a mode that was alien to judges. We address this specific issue in Sections 5 and 6, below.

We also conducted a second survey in which we contacted the creators of the 60 successful projects in our sample to determine the longer-term outcomes of their project. We used a modified version of a previously applied questionnaire [self-identifying citation omitted], and asked for a variety of qualitative and quantitative outcomes, including information about the audience of play as well as critical reviews. We supplemented this information with additional online searches, using Factiva and Google, to find other reviews of the productions funded through Kickstarter. Together, this material provides rich data on project outcomes along a variety of dimensions.

\footnotetext{
${ }^{4}$ One judge omitted some fields on one of the 6 projects that $s /$ he evaluated.
} 


\section{Data}

Since 10 sets of projects were evaluated by two judges each and the other 10 evaluated by one judge, we have a total of 180 evaluations for the 120 projects. For each response, we have basic information on the background of judges, such as their main affiliation with the theater community (academic, actor, critic, director, writer or other) and the number of national grant making institutions they have judged for in the past. For each project in the set that the judge evaluates, we have information on the judge's familiarity with the project, their rating of the project's novelty, relevance to the community, quality, feasibility and commercial viability. We also provide the judges with the funding goal of the project and ask them how much they would be willing to allocate to the given project, assuming they were not constrained in terms of the total funding they needed to allocate.

These 180 responses form the core of the data we use for this paper. However, we have two other sets of data that we match to the 120 projects. First, we have data on the attributes of the projects and their fundraising process on Kickstarter. For example, we know the location of the individual raising the funds, the number of individuals who pledged funding, and the total amount that was pledged (even when the goal was not successful), as well as the number of distinct reward levels that were developed to induce participation by the crowd. We also coded the number of videos and photographs the project displayed. Second, we have aimed to collect long-term outcome information on the projects, both through the survey of project founders and through web searches. The objective here is to try and codify the degree to which the individuals themselves, as well as external observers, deemed these projects to be commercial and artistic successes. These data are much more likely to be present for projects that were successful, so our main comparison is between projects that were funded by the crowd and were rated highly by experts and those that the crowd funded but were rated poorly by the experts. Our follow up survey of the Kickstarter projects that were successful yielded a $53 \%$ response rate (32 of the 60 projects), of which 28 completed all of the needed data, a high rate for webbased surveys (Kriauciunas, Parmigiani, \& Rivera-Santos, 2011). Further, we find no observable differences in the attributes of the projects for which there was a response and for which there was none. We use these survey responses to compare the longer term outcome of these funded projects. In addition to the survey results, we have attempted to code the degree of artistic success for these projects, using critical reviews in the press. 


\section{Results}

We start by outlining descriptive statistics on the projects in Table 1. Table 1 compares the evaluations of projects that achieved their funding goal on Kickstarter with those that did not succeed. The judges seem to consistently rate the successful projects higher than those that did not achieve their funding goal. Since there are 6 projects in each set, the probability that one of them will be ranked either the best or the worst is $1 / 6$. However, Table 1 shows that projects that were funded by the crowds were twice as likely to be ranked as the best project, while those that were unsuccessful were more than two times as likely to be ranked as the worst project by judges. Finally, even though judges were told that should provide a hypothetical funding as if they were unconstrained in allocating funds to projects, they greatly favored projects supported by the crowd, allocating an average of 1.5 times more funds to successful projects than those that were unsuccessful.

[Table 1 about here]

[Figure 2 about here]

There are two patterns that emerge from Table 1, which can be seen most clearly in Figure 2, which graphs the distribution of the judges combined scores for both successful and unsuccessful projects. First, there seems to be a strong and systematic positive correlation between the judgment of crowds and of experts: projects funded on Kickstarter are systematically evaluated as being better by experts. Second, this strong correlation does not tell the full story - the scores and the funding amounts proposed by the experts are not as stark as the decision about whether or not to fund projects, suggesting that there are projects that are funded on Kickstarter that do not seem to be highly rated by experts, and others that raised funding but were not as highly rated by experts. We probe these two patterns further in the following Tables.

[Table 2 about here]

In Table 2, we investigate the robustness of the positive correlations between expert evaluations and crowd funding, using the results from the first judge who responded for each project. Columns 1-3 report the coefficients on OLS regressions, where the dependent variable is the average score assigned to a project by the judges. The main variable of interest is an indicator variable that takes a value of 1 for projects that either met or exceeded their funding goal. Column 1 of Table 2 
reports the average scores of the two types of successful projects relative to the unsuccessful ones. Column 2 adds covariates related to the background of the judges, their experience with judging for grant-making foundations, and their prior familiarity with the specific projects in the survey they were asked to evaluate. Column 3 adds judge fixed effects to control for other fixed differences across judges, such as their average leniency or harshness, a bias in favor of or against theater projects raising money from the crowds, or a specific objective function they have for theater projects.

Moving across Columns 1-3 of Table 2 provides a very consistent picture of the strong correlation between the evaluation of judges and crowds. The inclusion of covariates and judge fixed effects increases the R-squared of the regressions considerably, implying these control variables add significant explanatory power to the regressions. Yet the coefficient on the indicator variables for success remain remarkably stable. ${ }^{5}$ The magnitudes on the coefficients are intuitive and relate to the magnitudes reported in Table 1. Unsuccessful projects score approximately 2.6 out of 5 on average, while those that reach or exceed their funding goals score about 3.2. ${ }^{6}$ Columns 4-6 repeat the same regressions, but where the dependent variable is now the funding share proposed by the experts for projects. They validate the results shown in Columns 1-3.

Table 2 therefore shows that, on average, the evaluation of equivalent projects by crowds and experts has a strong positive correlation. Moreover, it also documents that projects that exceed their goals are not the result of "the madness of crowds." Rather, if we use the expert evaluations as a benchmark of quality, it points to the fact that, on average, crowds do a good job of evaluating projects and screening the good from the bad.

The number of observations in the regressions in Table 2 is 120 rather than 180 because, although we have 2 sets of evaluations per project for half the projects, we have only included the first evaluation from each judge in order to provide consistency in terms of the weight given to each project

\footnotetext{
${ }^{5}$ This is also reassuring because it shows us that the patterns we see are not driven by some judges "picking at random" and others who might be 'peeking' at the outcomes and thereby providing results that were systematically correlated with project outcomes. We should note also that we explicitly asked judges whether they were familiar with projects and in only 2 of 180 did they respond that they were very familiar with a particular project.

${ }^{6}$ In unreported regressions, we find that although the point estimates for the projects that exceed their goal is always higher, a Wald test for the difference in the coefficient between the two types of successful projects cannot reject the hypothesis that they are the same.
} 
in the regression. This leads to the question as to whether our results are sensitive to the choice of judge.

In order to address the question of the sensitivity of results to our choice of judge, we start by noting that since we have 10 sets of projects with two judges each, 10 projects only had one judge each, we have $2^{10}$ (or 1 ,024) possible combinations of judges for the 10 sets. $^{7}$ To understand the role of the choice of judges, we look at all 1,024 combinations rather than just at the result of regressions from any one of these 1,024 combinations. This provides us with more confidence that we are not arbitrarily choosing a combination that happens to be statistically significant. We find the magnitude of the average score for successful projects ranges from 0.35 more than the unsuccessful to 0.7 more (with a mean of 0.52 larger). In all but two of the 1,024 combinations, the $p$-value is below 0.05 . The largest $p$ value is 0.06 , providing us with greater confidence that the results documented in Table 2 are statistically significant and robust to any of the other 1,023 combination of judges we might have picked in reporting our results. Similarly, the funding share results range from 0.18 more to 0.26 more for the projects that are successful on Kickstarter, and are always significant at the $5 \%$ significance level. Our results therefore document that there is a strong positive correlation between the evaluation by crowds and experts on projects.

Despite these positive results about the wisdom of crowds on average, it does not necessarily mean that they can perfectly substitute for experts in every instance - it is this heterogeneity between crowds and experts that we turn to next.

\section{Heterogeneity in Expert and Crowd Evaluations}

In order to examine heterogeneity in crowd and expert evaluations, we segment each of our 120 projects into one of four mutually exclusive categories - (1) those that are funded by both experts and crowds, (2) those that are funded by neither, (3) those funded only by experts and (4) those funded only by crowds. While we have outcome data on whether the crowd funded a project or not, we do not have actual funding decisions from experts. Rather, we have survey responses to a question asking them how much of the goal they would fund, assuming their grant-making budget was not constrained.

\footnotetext{
${ }^{7}$ As a simpler example, suppose we only had 4 sets, and had 2 sets that were sent to two judges (set 1 to judges $A$ and $B$, set 2 to judges $C$ and $D$ ) and 2 sets that we sent only to one judge (set 3 to judge $E$ and set 4 to judge $F$ ). In this case we would have $2^{2}$ or 4 unique combinations of judge evaluations across 24 projects: ACEF, ADEF, BCEF and BDEF.
} 
Our categorization of whether a judge hypothetically funded a project is thus based on our mapping of their responses to a hypothetical funding decision, one that is dependent on two factors. The first factor is the harshness of the screen we use - that is, whether we deem a project to be funded by a judge only if the judge funds the project a $100 \%$ or if we are willing to deem the project to be funded by experts when they only want to fund, say, $50 \%$ or $75 \%$ of the goal. Although it may seem like we only want to use $100 \%$ as the funding threshold (just like with the funding criterion on Kickstarter), our discussions with experts suggest that they routinely give projects that seem viable less money than requested and hence we do not necessarily want to use the most harsh screen when deemed projects as hypothetically funded by experts. Second, as above, since half the projects are evaluated by 2 judges, the question of whether the project was funded by experts potentially depends on which expert's funding choice we use.

[Table 3 about here]

While in theory these different empirical strategies can make large differences, in practice we find that the distribution of projects across buckets, and the overall patterns we show in the subsequent tables are quite insensitive to the specific categorization we choose. To help put this in perspective, in Table 3 we document how the distribution of the 120 projects across these four categories changes for the 1,024 different permutations outlined above across three different screens. The first two columns correspond to a categorization scheme where we assumed that a project would only be viable if the judge allocated $100 \%$ of the funding goal to the project. The next two correspond to a screen where the funding threshold is $75 \%$ and finally, the last two columns correspond to a screen where the funding threshold is $50 \%$.

Within each funding screen, we first report the degree of agreement between experts and crowds - that is the percentage of cases where they either both fund a project or both don't fund a project. The first row reports the average agreement for a given screen across all 1,024 combinations of judges. As can be seen from Columns 1, 3, and 5, there is a strong degree of agreement between experts and the crowds, around 59\% on average, and ranging from $56.7 \%$ to $65 \%$.

We demonstrate the strength of this correlation in two, related ways. First, we compare the extent of agreement in Table 3A to a hypothetical case where a judge funds projects at random (with a $50 \%$ probability). The simulations show that the percentage of agreement needs to be approximately $55.5 \%$ or more before we can conclude that agreement is not due to a random process at the $90 \%$ 
confidence interval and need to be $57.5 \%$ or more before we can conclude that agreement is not due to random process at the $95 \%$ confidence level. As can be seen from Table $3 \mathrm{~A}$, the minimum level of agreement using each screen is always greater than $55.5 \%$ and almost always greater than $57.5 \%$.

The second way we demonstrate the strength of the positive correlation is to run a regression where the dependent variable takes a value of 1 if there is agreement between the experts and crowds, and the key explanatory variable is where the project was successful on Kickstarter. The coefficient on the key variable of interest can be stated as $\rho=E[\mathrm{Yi} \mid \mathrm{Ci}=1]-E[\mathrm{Yi} \mid \mathrm{Ci}=0]$, where $\mathrm{Yi}$ is an indicator that takes the value of 1 if the judge funds the project $\mathrm{i}, \mathrm{Ci}=1$ if the crowd funded the project and $\mathrm{Ci}=0$ if the crowd did not fund the project. If the judge funds a project each time the crowd does and does not fund the project each time the crowd does not, then $E[Y i \mid C i=1]=1$ and $E[Y i \mid C i=0]=0$, leading the difference to be +1 (which, as one would like it to be, is perfect positive correlation). On the other hand, if the expert rejects a project each time the crowd funds it and funds the project each time the crowd does not, then $E[Y i \mid C i=1]=0$ and $E[Y i \mid C i=0]=1$, leading the difference to be -1 (which, as one would like it to be, is perfect negative correlation). Further, note that if the judge funds projects at random, then $E[Y i$ | $\mathrm{Ci}=1]=\mathrm{E}[\mathrm{Yi} \mid \mathrm{Ci}=0]$ and hence the correlation between the crowd and expert evaluation is zero. The requirement for the conditional expectations to be equal is that the projects be funded at random, rather than the specific probability of say $50 \%$. For example, a judge who used a stacked coin that funded every third project would still be as likely to fund a project that was funded by the crowd (1/3) as a project that was not funded by the crowd (still $1 / 3$ ). This is because with a random coin flip that is unrelated to whether the crowd did or did not fund the project, the $E[Y i] i s$ independent of $\mathrm{Ci}$, leading $\mathrm{E}[\mathrm{Yi} \mid \mathrm{Ci}=1]=\mathrm{E}[\mathrm{Yi} \mid \mathrm{Ci}=0]$. Therefore, under the null of random funding by the judges (at any approval rate), we should expect the coefficient in our regression to be zero.

We report the result from these regressions in Table 3B, where, as with Table 2, we pick the first judge who responded to each set in our survey. The results from Table 3B show that there is in fact a strong, positive correlation between judge and crowd evaluations, rejecting the null hypothesis that this could be due to random at the $5 \%$ confidence interval. Of course, as with Table 2 , we can check that our specific combination of judges is representative of the findings reported in Table 3B. We find that in every case our coefficients are significant at the $10 \%$ confidence interval, and in nearly $90 \%$ of the cases, they are also significant at the $5 \%$ confidence interval.

Despite these differences in categorization of projects, it can be seen that therefore that there is strong agreement between judges and crowds. Regardless of the screen used, we can almost always 
reject the hypothesis that the agreement was purely due to chance at the $95 \%$ confidence interval, and always reject it at the $10 \%$ confidence interval. This confirms the broad patterns we documented in Tables 1 and 2. However, Table 3A also documents that the "off diagonals" - the projects where the crowds and judges disagreed about the funding decision - represent about $40 \%$ of the projects and that these disagreements are most often comprised of projects that were rejected by experts but funded by the crowd. That is, among the projects where there is a disagreement, an overwhelming share - about three-quarters of the projects on average- are ones where the crowd chose to fund them but the experts did not.

In subsequent tables, we focus on two questions related to this heterogeneity. First, are there systematic differences in the attributes of the projects that are funded by only the crowd and only the experts? The second question arises from the fact that the majority of disagreements are constituted by projects funded by the crowd but rejected by experts. Given that many projects were funded by the crowd, but not by experts, are the results of these projects systematically different than those where experts and the crowd agreed? Since these projects were successfully funded on Kickstarter, we are able to examine real outcomes to study this issue. These questions get to the heart of the how the difference in the organization of crowds from that of experts may lead to different types of projects being funded.

\section{[Table 4 about here]}

In Table 4, we first examine whether there are systematic differences in the characteristics of projects that were funded only by the crowds compared to those funded only by experts. ${ }^{8}$ To do so, we run OLS regressions, where the dependent variable is the specific characteristic we are examining, and the main right hand side variables are indicators for whether the project fell in one of the four mutually exclusive categories outlined above. The projects that were funded by neither the crowd nor the experts are treated as the omitted, reference category, so all coefficients can be interpreted as deviations from this baseline. The specific screen we use for these regressions is one where the funding threshold is $75 \%$. All regressions include judge fixed effects and the set of control variables used in Table 2. We report robust standard errors that are clustered by judge.

\footnotetext{
${ }^{8}$ From this point on, we now focus on the combination of judges that were used in the regressions in Table 2 and $3 B$ that have been shown to be quite typical of the 1,024 possible combinations of judges we might have used.
} 
Table 4 shows some interesting patterns. First, projects that were not liked by either the crowds or judges had larger funding goals than any of the other three categories. Projects that were funded had systematically lower funding goals, although a large funding goal does not account for why the crowd did not fund the subset of projects that the experts liked that were unsuccessful on Kickstarter. Columns 2-6 provide an explanation for why this may be the case. Column 2 documents that projects that were ultimately funded (rows (a) and (c)) have significantly larger average funding amounts than those that were funded only by the experts (row (b)). A Wald test for the difference in coefficients shows that these differences are also statistically significant. That is, it seems that while the funding goals were not different, projects that the crowds liked had significantly larger average funding amounts compared to those that were not funded. Note that average funding size is a relevant metric since Kickstarter collects and keeps data on all those who commit funding to projects even when the project is unsuccessful in meeting its goal. This is because commitments are made in a continuous manner, but are only "drawn upon" when the project has met its goal. Thus, we still have instances where some individuals have committed funding to unsuccessful projects. In these instances, we find that the average funding amounts are significantly lower. This is most easily seen by looking at Figure 2 .

The pattern seen in Figure 2 could be for two reasons. First, those who were successful could be connected to a wealthier network, so that they are able to get larger commitments from their backers and hence more easily reach their goal. This might be particularly true because studies of crowdfunding suggest that friends and family are often a critical base for campaigns (Agrawal et al., 2010) ${ }^{9}$. The second explanation is that there are systematic differences in the ways in which the two groups approach fundraising on Kickstarter, and that the differences in commitments are an indication of the skill associated with raising money from crowds. ${ }^{10}$ Of course, these are not mutually exclusive explanations and both could be true. The evidence presented in Table 4 is certainly consistent with theory that there are differences in fundraising approaches, and provides some suggestive evidence that networks may also be important. Columns 3 and 4 of Table 4 show that projects that successfully raise

\footnotetext{
${ }^{9}$ In our follow-up survey of successful projects, project creators suggested that friend and family support was important, but probably not the provider of the majority of funding. In a five point Likert scale ranging from "strongly disagree" to "strongly agree," the mean answer to the question "My backers were mostly friends and family" was 3.7 , s.d. $=1.1$,

${ }^{10}$ Note that there is also the possibility that projects that offered a higher consumption utility (say because people wanted to watch the play) raised higher amounts through ticket sales. As we note later, this was not the case, so we do not focus on this possible mechanism.
} 
money from crowds provide a greater number of reward levels for the crowds and also more commonly post "updates" about their project within the first three days after launch. This is equally true for rows (a) and (c), but we can see that row (b) is significantly different. Moreover, Columns 5 and 6 document that the projects that were rated highly by experts but did not raise money from crowds also did not provide as many pictures or videos as those that were successful. In addition, Column 7 suggests that the language in the projects that were funded only by experts tended to be more formal ${ }^{11}$ than those funded by only the crowd, suggesting that crowds may have a disposition towards less formal language. Together, columns 3-7 paint a consistent picture: raising money from the crowd seems to involve a skill that may be independent of the quality of the project (in much the same way as raising money from experts requires skill). Those who do not pitch to the crowd in an appropriate way may not be successful in raising money, even if the quality of the underlying project is high ${ }^{12}$.

Columns 8 and 9 examine the hypothesis that those who are successful in raising money from crowds may have better or wealthier networks. Column 8 shows that those who were successful had the same network size, as proxied by the number of Facebook friends. A difference in funding commitment for a similar size of network could be consistent with wealthier friends and family, although it could also proxy for the skill in approaching the crowd. In Column 9, we show that those projects that only the crowd liked were somewhat more likely to be based in New York or California this could proxy for the wealth of the local network or again, could proxy for savviness with social media and running crowdfunding campaigns. Alternatively it could also be due only to the degree of diffusion of the Kickstarter platform in these two states. On balance, we find the strongest evidence for systematic differences in raising crowd funding as stemming from skill in running such campaigns, although we cannot rule out that this was also due to differences in networks. Further evidence of the role of skill in crowdfunding stems from the fact that the attributes of projects funded by both the

\footnotetext{
${ }^{11}$ Our measure of formality in this context is the share of words in the proposal that were longer than 6 letters, as studies have shown that longer world length in a body of text is correlated with the level of formality in that text (Brooke, Wang, \& Hirst, 2010; Karlgren \& Cutting, 1994). We also have some qualitative evidence that proposals that used swear words were less likely to be funded by experts, suggesting that informality may be punished.

${ }^{12}$ These factors of the pitch tend to be established prior to the launch of a crowdfunding campaign. For updates, we follow Mollick (2014) and only measure whether projects were updated in the first three days after launch, reducing the risk that updates are a reaction to success. At the same time, we cannot rule out that these factors could be changed in reaction to the crowd and are careful, therefore, not to push a causal explanation for these differences.
} 
crowd and experts (row (a)) are more similar to those funded by only the crowd (row (c)) than each of these is to those funded only by experts (row (b)).

Next, we consider how judges rate projects that are supported by the crowd alone compare to those that are not. Table 5 provides the differences in scores attributed to these projects by our experts. The specifications run in Table 5 are identical to those in Table 4, with the exception that the dependent variables are dimensions along which the experts were asked to evaluate the projects. The high scores associated with rows (a) and (b) are mechanical, in that these are projects that the experts would have funded. Nevertheless, it is worth noting that the projects that the crowd and experts funded rank higher than those funded only by experts, again reinforcing the notion that the projects where both crowds and experts agree to fund are likely to be extremely high quality.

Looking at row (c) is also instructive since it shows that the point estimates are consistently higher than the omitted category, although they are often imprecisely estimated so that the differences are not statistically significant. That is, there is a subset of projects that the crowd funded that the experts found no better than the omitted category (those that neither the crowd nor experts liked). Indeed, our survey of the successful Kickstarter projects suggests that this was also true to experts in general: the subset that only the crowd funded raised an average of $\$ 1,900$ from institutional sources prior to the campaign compared to $\$ 4,850$ for those that the experts and crowds funded. That is, our finding that experts did not rate these projects as highly seems to be broadly representative of how other experts may have also viewed these projects. Nevertheless, it is interesting that the one column where there is a statistically significant difference between row (c) and the omitted category is around the quality of the project. That is, among projects that the experts chose not to fund, those that were funded by the crowd were deemed to be higher quality projects by the experts than those that the crowd did not fund (although, of course they were also ranked as lower quality than rows (a) and (b)). Again, this supports the notion that even when there is disagreement between crowds and experts on the funding decision, there still seems to be some level of congruence in terms of the broad sense of which projects are higher quality.

In Tables 6 and 7, we turn to qualitative evidence about the longer-term outcomes of projects. We relied on survey data for information on both audience size and the degree to which projects succeeded or failed at meeting their audience goals. We also asked respondents to provide links or excerpts from reviews. In all cases, we also attempted to locate reviews ourselves by searching for the project on Factiva and on Google. To be conservative, we classified projects in one of four ways: We considered 
projects to be failures if they received only bad reviews and did not run for their full length. ${ }^{13}$ Successes made up the vast majority of projects. These were projects that ran for their intended length but did not earn rave reviews from national publications, though they may have received good local press. This category contains a wide range of projects, some much more successful than others, as indicated by the qualitative data in the tables. Finally, we categorized projects as commercial hits if they had substantially extended runs in front of large crowds, and as critical hits if they received either rave reviews from national publications, or else won prestigious theater awards.

In Table 6, we look at the long-term outcome of the projects that both crowds and experts funded. We have survey responses that include self-reported outcome data on 11 of the 22 such projects. Using our conservative coding regime, none of these projects failed, and one turned into a commercial hit. Examining the more detailed qualitative data, it is apparent that there were a wide variety of critical and commercial outcomes, but a relative dearth of either clear failures or runaway successes. Though these results are tentative, most projects selected by both the crowd and experts appeared to deliver on their promise, with some variation in the critical and commercial acclaim achieved.

In Table 7, we re-create this for projects that the crowd funded, but which the experts did not. Here we have self-reported outcome data on 17 out of the 38 productions. Remarkably, we find quite a similar pattern, with the vast majority of projects achieving the same level of success as the projects endorsed by the experts. To the extent that there are differences, there is one failure among the crowdselected projects, and four projects that we could consider hits. Two of these hits are critical, rather than commercial, successes - an ironic outcome, given that these performances were rejected by the expert critics, but embraced by the crowd, in the funding stage. We find that the broad picture is one where $94 \%$ of the funded projects supported by the crowd alone had at least moderate success, and $24 \%$ were extremely successful, some artistically, and some commercially. This compares to a $100 \%$ success rate from the projects backed by both crowds and experts, of which $9 \%$ were extremely successful ${ }^{14}$.

\footnotetext{
${ }^{13}$ One concern about crowdfunding has been that some projects may fail to deliver entirely, either because of malicious intent or else failure on the part of the project creators. We found only one example of this sort of project, in this case due to the death of a project creator, adding to research suggesting fraud on Kickstarter is uncommon (Mollick, 2014)

${ }^{14}$ While we did not have survey results for the remaining 32 projects, we did seek to establish whether or not critical reviews of the projects indicated any substantial deviation from that observed in the projects for which we had survey results. We did not locate any indication of a systematic difference. Of the 11 projects that did not
} 
We also endeavored to examine the outcomes of the 11 projects selected by experts but not funded by the crowd. We were able to determine that seven of these projects were ultimately staged. All seven would be considered minor successes, but none achieved high levels of critical notice, or substantial commercial success.

Although we hesitate to draw broad conclusions from the limited data, we find it interesting that within the bucket of projects unfunded by experts, the experts do seem to give higher ratings to projects that were ultimately more successful. This suggests that the screen used by the crowd is somewhat lower, but not entirely without merit (although the crowd also funded the only project to fail dramatically). These results are suggestive of a case where the crowd selects some projects with greater variability in potential outcome than experts, resulting in more failures, but more breakout hits, than the experts, similar to findings about how the structure or the number of participants in screening can generate more high quality and low quality ideas (Sah \& Stiglitz, 1986; Terwiesch \& Ulrich, 2009; Terwiesch \& Xu, 2008).

A possible alternative explanation of the ability of the crowd to pick successful projects is that the crowd might serve as the factor that makes these products succeed. By pre-purchasing tickets through Kickstarter (one of many potential rewards offered by artists), they may be assuring the success of these shows. Using our survey data, we examined the 14 projects that provided us with estimates of total ticket sales. Together, these projects sold 25,779 tickets overall, of which 961 were pre-sold through Kickstarter, or less than 4\%. Pre-sales on Kickstarter did not seem to account for the success of these shows, based on this measure. Further, pre-sales would not be predictive of critical acclaim, which also seemed to accrue disproportionately to projects backed by the crowd alone.

\section{Discussion}

Given the rise of crowds as a vital part of decision-making in areas ranging from product design to entrepreneurship, the question of how the judgment of crowds compares to that of experts is of great

answer the survey but which were supported by the crowd and the experts, 10 appeared to be successes, with 1 project failing due to the death of a key member of the theater troupe. Of the 21 projects that were funded only by the crowd, at least 1 was a critical success, winning a prestigious theater award, while 2 others appeared to win less prestigious theater honors. Additionally, 2 were partial failures, having delivered some of the performances promised in their campaign, but not all, although both projects promised to finish delivery in 2014 or 2015, and still appeared to enjoy backer support. These results align with those from the survey group, suggesting that there does not appear to be large hidden biases in Tables 6 and 7, but that if anything, the crowd seems to be associated with slightly more variance in outcomes. 
importance. While there have been some signs that crowds could act wisely, most examples of crowd wisdom either include experts that ultimately exercise final judgment, as in crowdsourcing (Afuah \& Tucci, 2012; Poetz \& Schreier, 2012) or compare aggregated predictions to those of individuals (Budescu \& Chen, 2014; Larrick \& Soll, 2012; Wolfers \& Zitzewitz, 2004). Crowdfunding, like other emerging areas where crowds act without intermediaries or secondary markets, operates differently, heightening the risk that the crowd could be "mad" - subject to irrational exuberance, follies of group decision-making, or other collective pitfalls. Further, even if crowds are not directly irrational, they could still only express idiosyncratic or popular tastes, ignoring proposals that would normally be supported by experts.

The first contribution of our work is to document strong congruence in the judgment of crowds and experts in a highly subjective environment such as theater, even outside of prediction markets or forecasting competitions. These results were robust to many kinds of measurement. Further, we see no signs that, for those decisions where crowds and experts diverge, that the decisions supported by the crowd alone perform systematically worse than those of the experts. The projects selected by the crowd succeeded $93 \%$ of the time, while those selected by crowds and experts succeeded $100 \%$ of the time. However, among the successes, the crowds also seemed associated with bigger hits, suggesting more variability in the outcomes rather than a lower mean.

Our results also shed light on the differences between crowd and expert judgment. The biggest differences we found between projects that the crowd alone supported versus those supported by experts seemed to be in the style of presentation, rather than the quality of the actual project itself. The more "crowdfunding friendly" a quality proposal was - taking advantage of the internet by using videos and pictures, including many rewards for backers, and so on - the more it seemed to appeal to the crowd. Similarly, experts also seem to have signals that they look for - for example the degree of formality of a proposal, or the presence of swear words. Our results suggest that these differences in tastes can have meaningful real outcomes, in that the crowd seems willing to fund projects that experts are not, even when experts are given unlimited funds and similarly, the crowd seems to systematically miss projects that experts like because they are not pitched in a "crowdfunding friendly" format.

In this sense, our paper provides evidence of the important role crowdfunding can have in democratizing entry among projects that experts might have rejected. For example, crowdfunding provides the possibility of funding to individuals who would not otherwise have access to funds because of the potential challenges of applying for NEA grants: they may not have experience or knowledge of grant writing, may have the wrong skillset to apply, or may be proposing programs that are not within 
NEA guidelines. ${ }^{15}$ Based on this evidence, the change from a hierarchical expert-led system to a mixed expert and crowd-based one may have large positive effects on the types of innovations that the system produces (Sah \& Stiglitz, 1986), as allowing more ideas to come to fruition has been shown to lead to increased innovation quality (Kornish \& Ulrich, 2011; Terwiesch \& Ulrich, 2009). Similarly, a more diverse pool of individual innovators can further increase innovation ( $\varnothing$ stergaard, Timmermans, \& Kristinsson, 2011).

It is important to note that, while we find encouraging evidence for the value of crowd decisionmaking, this does not devalue the role of experts. For example, some discussions with experts showed more willingness to fund more artistically challenging work that may not appeal to the crowd. Experts may also be less swayed by the salesmanship of the pitch, as evidenced by the lower importance they appeared to place on the multimedia in the pitch itself. Our results are consistent with, and indeed support, the notion that in a crowd-based decision regime there is still a critical place for expert judges. In fact, we aim to stress that our setting and research design does not allow us to speak definitively to the important and pertinent policy question of what would happen to theater projects if we shifted from a purely expert-funded model to a purely crowd-funded one. This is because we are focused on projects that applied to a crowd funding site rather than the universe of artistic projects that might be available $^{16}$. For example, some have argued that the growing importance of Kickstarter in the funding of the arts reduces the need for the government to provide funding to such endeavors through the NEA, which has an annual operating budget of about $\$ 150$ million. Although our results suggest that crowdfunding can play an important role to complement such organizations, we are less well-positioned to speak to questions related to how a decrease in theater grants from the NEA would impact the nature

\footnotetext{
${ }^{15}$ As noted above, there are some suggestions in the data that the crowd may be more willing to take a chance on projects with higher variance outcomes than experts might be comfortable with. Though it is not statistically testable, we find that the crowd funded a higher percentage of hits (27\%) than the experts (7\%), and also the only project that failed due to a quality issue. Increasing the number of high variance projects may lead to more breakthrough ideas.

${ }^{16}$ Consider the following example: Say of 10 projects $p 1-p 10$, the crowd would fund $p 1-p 3$, neither crowds nor experts would fund $p 4$ and experts would fund $p 5-p 10$. If a study sample contained only projects $p 1-p 6$, say because p7-p10 were not conducive to being listed on a crowdfunding site, then showing that a majority p1-p6 were funded by the crowd does not tell us anything about whether the crowd-only or expert-only system is better. In this example, if one were to choose between a crowd-funded or expert-funded system, the expert-based one would fund six projects compared to only three under a purely crowd-funded system even though the sample in question had a lower share of projects funded by experts. This is why one would need the universe of projects, together with project fixed effects to effectively address this policy question. We thank a referee for clarifying this issue.
} 
and style of theater productions in the United States, especially theater produced by underrepresented groups, or works that are artistically challenging.

Although our analysis was conducted for theater projects, we feel that our key result, that experts demonstrate a strong congruence with projects funded by the crowd, is likely to generalize to other settings where the crowd is an end user for the product being financed and hence might be well positioned to judge the project. While this is likely to be true for many aspects of the arts, such as film, music and dance, we believe that there are also aspects of technological innovation where crowds can play a key role in complementing experts as sources of capital. Kickstarter has proven to be an influential source for innovations in areas as gaming and consumer-facing internet technologies, as well as more specialized areas such as wearable computing and 3D printing. Indeed, a number of startups that have raised funding on Kickstarter have gone on to raise institutional venture capital suggesting the growing role that the crowd can play in providing validation of "traction" for experts. ${ }^{17}$

Our research has some limitations and strengths. One limitation is our study stems from the research design: we chose to restrict our analysis to a set of projects where, ex ante, we believed there to be overlap in the types of projects that were funded by the crowd and the types of projects our experts would evaluate in other settings, such as when reviewing for the NEA or foundations. We thus restricted our study to theater projects seeking at least $\$ 10,000$. While we believe that theater offers a conservative test of crowd wisdom, given its subjective nature and the divide between critics and customers, we cannot necessarily generalize these findings to all other forms of crowd judgment. Furthermore, our results speak to crowd funding behavior conditional on the funding size we studied. If projects seeking much smaller funding, even within theater, are more frivolous or associated with different crowdfunding motivations, our findings will not apply to them. Second, while our outcome data is strongly suggestive of similar outcomes between the crowd only and the expert and crowd backed projects, it is circumstantial in nature, and hard to measure directly. Third, we focus only on projects that applied for crowdfunding, rather than the universe of all theater projects, which implies that we are limited in our ability to speak to which screening regime (crowds vs. experts) is better suited

\footnotetext{
${ }^{17}$ For example, Kerr, Nanda, and Rhodes-Kropf (2014) document the difficulty that even professional investors have in predicting which investments are likely to be successful. Indeed, there seems to be a growing move among early stage investors to demonstrate 'traction' with customers, as is demonstrated by platforms such as AngelList profiling these metrics for potential investors.
} 
to the projects applying for funding or to address the question of how a shift from one funding regime to another might impact which projects are commercialized.

Despite these limitations, however, our approach also has strengths. A key strength is that by using panels of expert judges to evaluate existing projects, we were able to avoid many of the endogenity concerns that might otherwise arise in such studies. Further, the opinions of judges on projects are robust to judge fixed effects, suggesting that our results are not purely the result of idiosyncratic views of some judges. Additionally, we were able to use field data representing actual crowd decisions from the largest crowdfunding platform, observing both successful and failed projects.

\section{Conclusion}

Our study offers the first detailed comparison of crowd and expert judgment, an issue of increasing relevance in a world where crowdfunding, crowdsourcing, crowdscience, and related concepts are increasing in popularity, and where billions of dollars are being deployed through crowdfunding platforms. In particular, we can effectively address the extent to which experts agree or disagree with the funding decisions of the crowd, and thereby use this as a benchmark for the wisdom of crowds. We find that the crowd is more wise than mad, generally agreeing with the experts, and that, on average, the projects selected by the crowd alone seem to do as well as those selected by experts. For academics, our work highlights the need to better understand the ways in which crowd decisions are made and the circumstances under which the crowd, experts, or a combination should be deployed to address particular needs. Practically, this paper suggests that crowdfunding may be a viable source of entrepreneurial financing, for both cultural projects and traditional startups. The crowd has the potential to increase innovation, lower barriers to entry, and democratize the entrepreneurial process by allowing more ideas to compete in the marketplace, particularly as a complement to expert judgment. 


\section{References}

Afuah, A., \& Tucci, C. L. (2012). Crowdsourcing as a solution to distant search. Academy of Management Review, 37(3), 355-375.

Agrawal, A., Catalini, C., \& Goldfarb, A. (2010). The Geography of Crowdfunding. SSRN Electronic Journal. doi:10.2139/ssrn.1692661

Agrawal, A., Catalini, C., \& Goldfarb, A. (2013). The Simple Economics of Crowdfunding. Policy and the Economy, 14, 1-46.

Bahrami, B., Olsen, K., Bang, D., Roepstorff, A., Rees, G., \& Frith, C. (2012). What failure in collective decision-making tells us about metacognition. Philosophical Transactions of the Royal Society B: Biological Sciences, 367(1594), 1350-1365.

Balaratnasingam, S., \& Janca, A. (2006). Mass hysteria revisited. Current Opinion in Psychiatry, 19(2), 171-174.

Banerjee, A. V. (1992). A simple model of herd behavior. The Quarterly Journal of Economics, 107(3), 797-817.

Barsade, S. G. (2002). The ripple effect: Emotional contagion and its influence on group behavior. Administrative Science Quarterly, 47(4), 644-675.

Baum, J., \& Silverman, B. (2004). Picking winners or building them? Alliance, intellectual, and human capital as selection criteria in venture financing and performance of biotechnology startups. Journal of Business Venturing, 19(3), 411-436.

Bikhchandani, S., Hirshleifer, D., \& Welch, I. (1992). A theory of fads, fashion, custom, and cultural change as informational cascades. Journal of Political Economy, 992-1026.

Bogers, M., Afuah, A., \& Bastian, B. (2010). Users as innovators: a review, critique, and future research directions. Journal of Management, 36, 857-875.

Boudreau, K., Lacetera, N., \& Lakhani, K. (2010). The Effects of Increasing Competition and Uncertainty on Incentives and Extreme-Value Outcomes in Innovation Contests. Harvard Business School.

Boudreau, K., Lacetera, N., \& Lakhani, K. (2011). Incentives and Problem Uncertainty in Innovation Contests: An Empirical Analysis. Management Science, 57(5), 843-863.

Bourdieu, P. (1975). The specificity of the scientific field and the social conditions of the progress of reason. Social Science Information, 14(6), 19-47. doi:10.1177/053901847501400602

Bourdieu, P. (1984). Distinction: A social critique of the judgement of taste. Harvard University Press. 
Brooke, J., Wang, T., \& Hirst, G. (2010). Automatic acquisition of lexical formality. In Proceedings of the 23rd International Conference on Computational Linguistics: Posters (pp. 90-98). Association for Computational Linguistics.

Budescu, D. V, \& Chen, E. (2014). Identifying Expertise to Extract the Wisdom of Crowds. Management Science, Forthcoming.

Caves, R. E. (2000). Creative industries: Contracts between art and commerce. Harvard University Press.

Caves, R. E. (2003). Contracts between art and commerce. Journal of Economic Perspectives, 73-84.

Chen, D., \& Lin, Z. (2014). Rational or Irrational Herding in Online Microloan Markets: Evidence from China. Available at SSRN 2425047.

Chen, M. (2008). Modeling a presidential prediction market. Management Science, 54(8), 1381-1394.

Cipriani, M., \& Guarino, A. (2005). Herd behavior in a laboratory financial market. American Economic Review, 1427-1443.

Clauson, K. A., Polen, H. H., Boulos, M. N. K., \& Dzenowagis, J. H. (2008). Scope, completeness, and accuracy of drug information in Wikipedia. The Annals of Pharmacotherapy, 42(12), 1814-21. doi:10.1345/aph.1L474

Cohen, J. (1968). Weighted kappa: Nominal scale agreement provision for scaled disagreement or partial credit. Psychological Bulletin, 70(4), 213.

Congress, 112th. Jumpstart Our Business Startups Act (2012). US.

Devenow, A., \& Welch, I. (1996). Rational herding in financial economics. European Economic Review, $40(3), 603-615$.

DiMaggio, P. (1991). Cultural entrepreneurship in nineteenth-century Boston. Rethinking Popular Culture: Contemporary Perspectives in Cultural Studies, 374.

Earley, P. C. (1989). Social loafing and collectivism: A comparison of the United States and the People's Republic of China. Administrative Science Quarterly, 565-581.

Eliashberg, J., \& Shugan, S. M. (1997). Film critics: Influencers or predictors? The Journal of Marketing, 68-78.

Ferrary, M., \& Granovetter, M. (2009). The role of venture capital firms in Silicon Valley's complex innovation network. Economy and Society, 38(2), 326-359.

Franzoni, C., \& Sauermann, H. (2014). Crowd science: The organization of scientific research in open collaborative projects. Research Policy, 43(1), 1-20. doi:10.1016/j.respol.2013.07.005 
Gans, H. (2008). Popular Culture and High Culture: An Analysis and Evaluation Of Taste (Revised And Updated). Basic Books.

Giles, J. (2005). Internet encyclopaedias go head to head. Nature, 438(7070), 900-901.

Ginsburgh, V. (2003). Awards, success and aesthetic quality in the arts. The Journal of Economic Perspectives, 17(2), 99-111.

Goldfarb, B. (2008). The effect of government contracting on academic research: Does the source of funding affect scientific output? Research Policy, 37(1), 41-58.

Gompers, P., \& Lerner, J. (2004). The venture capital cycle. MIT Press.

Greenstein, S., \& Zhu, F. (2012). Is Wikipedia Biased? The American Economic Review, 102(3), 343-348.

Greenstein, S., \& Zhu, F. (2014). Do Experts or Collective Intelligence Write with More Bias: Evience from Encyclopedia Britannica and Wikipedia (No. 15-023).

Hellmann, T., \& Puri, M. (2002). Venture Capital and the Professionalization of Start-up Firms: Empirical Evidence. The Journal of Finance, 57(1), 169-197.

Isenberg, D. (2012). The Road to Crowdfunding Hell, Harvard Business Review Online, retrieved from https://hbr.org/2012/04/the-road-to-crowdfunding-hell/.

Janis, I. L. (1982). Groupthink: Psychological Studies of Policy Decisions and Fiasces. Houghton Mifflin.

Jeppesen, L., \& Frederiksen, L. (2006). Why do users contribute to firm-hosted user communities? The case of computer-controlled music instruments. Organization Science, 17(1), 45.

Karlgren, J., \& Cutting, D. (1994). Recognizing text genres with simple metrics using discriminant analysis. In Proceedings of the 15th conference on Computational linguistics-Volume 2 (pp. 10711075). Association for Computational Linguistics.

Kerr, W. R., Nanda, R., \& Rhodes-Kropf, M. (2013). Entrepreneurship as Experimentation.

Kim, B. K., \& Jensen, M. (2011). How product order affects market identity repertoire ordering in the US opera market. Administrative Science Quarterly, 56(2), 238-256.

Kornish, L. J., \& Ulrich, K. T. (2011). Opportunity spaces in innovation: Empirical analysis of large samples of ideas. Management Science, 57(1), 107-128.

Kortum, S., \& Lerner, J. (2000). Assessing the contribution of venture capital to innovation. RAND Journal of Economics, 31(4), 674.

Kriauciunas, A., Parmigiani, A., \& Rivera-Santos, M. (2011). Crowdfunding creative ideas: the dynamics of projects backers in Kickstarter. Strategic Management Journal, 32(9), 994-1010. 
Kuppuswamy, V., \& Bayus, B. L. (2013). Crowdfunding Creative Ideas: The Dynamics of Project Backers in Kickstarter. SSRN Electronic Journal.

Larrick, R., Mannes, A., \& Soll, J. (2012). The social psychology of the wisdom of crowds. Frontiers in Social Psychology: Social Judgment and Decision Making, 227-242.

Larrick, R., \& Soll, J. (2012). Intuitions about combining opinions: Misappreciation of the averaging principle. Management Science, 52(1), 111-127.

Latane, B., Williams, K., Harkins, S., \& Latané, B. (1979). Many hands make light the work: The causes and consequences of social loafing. Journal of Personality and Social Psychology, 37(6), 822.

Mackay, C. (1852). Extraordinary Popular Delusions and the Madness of Crowds. Extraordinary popular delusions and the madness of crowds (Second Edi., p. ix,214p.). London: Richard Bentley.

Makridakis, S., \& Winkler, R. L. (1983). Averages of forecasts: Some empirical results. Management Science, 29(9), 987-996.

Mollick, E. (2014). The Dynamics of Crowdfunding: Determinants of Success and Failure. Journal of Business Venturing, 29(1), 1-16.

Mollick, E., \& Kuppuswamy, V. (Forthcoming). Crowdfunding: Evidence on the Democratization of Startup Funding. In K. Lakhani \& D. Harhoff (Eds.), Revolutionizing Innovation: Users, Communities and Openness. MIT Press.

Nanda, R., \& Rhodes-Kropf, M. (2012). Financing risk and innovation. Harvard Business School Entrepreneurial Management Working Paper, (11-013).

Nelson, R. R. (1959). The Simple Economics of Basic Scientific Research. Journal of Political Economy, 67.

O'Mahony, S. (2003). Guarding the commons: how community managed software projects protect their work. Research Policy, 32(7), 1179-1198.

$\emptyset$ stergaard, C. R., Timmermans, B., \& Kristinsson, K. (2011). Does a different view create something new? The effect of employee diversity on innovation. Research Policy, 40(3), 500-509.

Peterson, R. A., \& Kern, R. M. (1996). Changing highbrow taste: from snob to omnivore. American Sociological Review, 900-907.

Poetz, M., \& Schreier, M. (2012). The value of crowdsourcing: can users really compete with professionals in generating new product ideas? Journal of Product Innovation Managment, 29(2).

Raafat, R. M., Chater, N., \& Frith, C. (2009). Herding in humans. Trends in Cognitive Sciences, 13(10), 420-428.

Rajagopalan, M. S., Khanna, V. K., Leiter, Y., Stott, M., Showalter, T. N., Dicker, A. P., \& Lawrence, Y. R. (2011). Patient-oriented cancer information on the internet: a comparison of wikipedia and a 
professionally maintained database. Journal of Oncology Practice / American Society of Clinical Oncology, 7(5), 319-23.

Ray, R. (2006). Prediction Markets and the Financial" Wisdom of Crowds." The Journal of Behavioral Finance, $7(1), 2-4$.

Reinstein, D. A., \& Snyder, C. M. (2005a). The influence of expert reviews on consumer demand for experience goods: A case study of movie critics. Journal of Industrial Economics, 53(1), 27-51.

Reinstein, D. A., \& Snyder, C. M. (2005b). The influence of expert reviews on consumer demand for experience goods: A case study of movie critics. The Journal of Industrial Economics, 53(1), 27-51.

Sah, R. K., \& Stiglitz, J. E. (1986). The Architecture of Economic Systems: Hierarchies and Polyarchies. The American Economic Review, 76(4), 716-727.

Scharfstein, D. S., \& Stein, J. C. (1990). Herd behavior and investment. The American Economic Review, 465-479.

Schulz-Hardt, S., Brodbeck, F. C., Mojzisch, A., Kerschreiter, R., \& Frey, D. (2006). Group decision making in hidden profile situations: dissent as a facilitator for decision quality. Journal of Personality and Social Psychology, 91(6), 1080.

Schumpeter, J. (1942). Capitalism, Socialism and Democracy. Economica (Vol. 11, p. 40). Harper.

Shane, S., \& Venkataraman, S. (2003). Guest editors' introduction to the special issue on technology entrepreneurship. Research Policy, 32(2), 181-184.

Shrum, W. (1991). Critics and publics: Cultural mediation in highbrow and popular performing arts. American Journal of Sociology, 97(2), 347-375.

Simmons, J. P., Nelson, L. D., Galak, J., \& Frederick, S. (2011). Intuitive biases in choice versus estimation: Implications for the wisdom of crowds. Journal of Consumer Research, 38(1), 1-15.

Surowiecki, J. (2004). The wisdom of crowds: Why the many are smarter and how collective wisdom shapes business, economies, societies, and nations (p. 336). New York: Random House.

Terwiesch, C., \& Ulrich, K. (2009). Innovation tournaments: Creating and selecting exceptional opportunities (p. 256). Harvard Univ Pr.

Terwiesch, C., \& Xu, Y. (2008). Innovation contests, open innovation, and multiagent problem solving. Management Science, 54(9), 1529-1543.

Tetlock, P. (2005). Expert political judgment: How good is it? How can we know?. Princeton University Press.

Von Hippel, E. (1986). Lead users: A source of novel product concepts. Management Science, 32(7), 791805. 
Wenger, E. C., \& Snyder, W. M. (2000). Communities of practice: The organizational frontier. Harvard Business Review, 78(1), 139-146.

Wijnberg, N. M., \& Gemser, G. (2000). Adding value to innovation: Impressionism and the transformation of the selection system in visual arts. Organization Science, 11(3), 323-329.

Wolfers, J., \& Zitzewitz, E. (2004). Prediction Markets. Journal of Economic Perspectives, 18(2), 107-126.

Woronkowicz, J., Nicols, B., \& Iyengar, S. (2012). How the United States funds the arts. National Endowment for the Arts.

Zhang, J., \& Liu, P. (2012). Rational herding in microloan markets. Management Science, 58(5), 892-912.

Zuckerman, E. (1999). The categorical imperative: securities analysts and the illegitimacy discount. American Journal of Sociology, 104(5), 1398-1438. 


\section{Figure 1: Example of a Project}

This example project was funded by the crowd, but not by judges. It was a commercial success, with 48 shows at a 300 seat theater that were $2 / 3$ to completely full and tickets priced at $\$ 24-\$ 44$. It also received positive local reviews, including the Best Local Musical and four other awards by BroadwayWorld, as well as generally positive reviews from local papers, such as the San Francisco Examiner: "This is their first original production and is definitely worth it. I had such a good time that I will likely be going back."

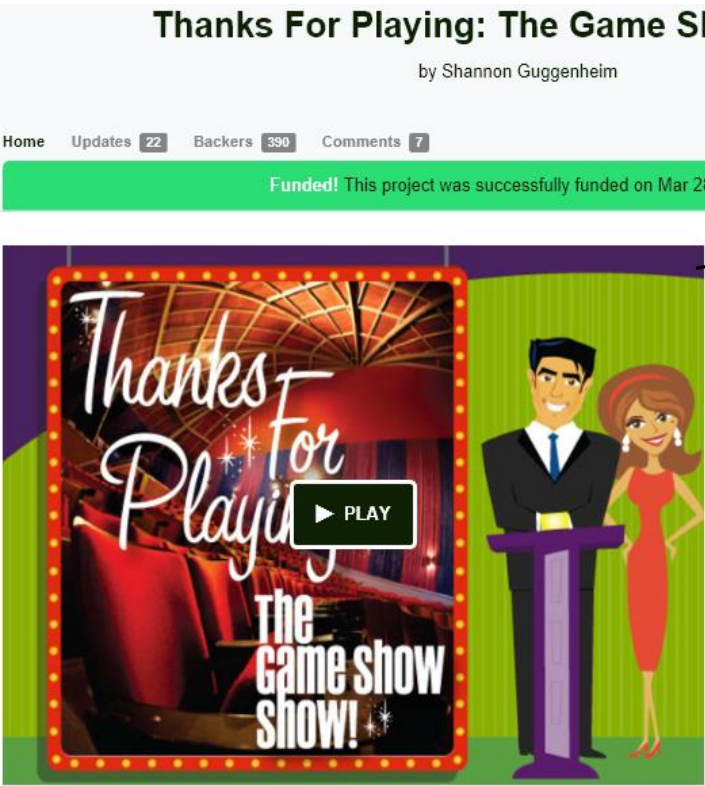

If Share $<0 \quad$ Tweet $\langle$ Embed

The team behind the magic at The Retro Dome is working on a brand new musical, that celebrates America's favorite pastime: Game Shows!

Support the creation of a LIVE MUSICAL

COME ON DOWN!! You have the opportunity to be a part of the creation of the world premiere musical, THANKS FOR PLAYING: THE GAME SHOW SHOW!

From the creative minds that brought you, The MeshugaNutcracker! and the producers of such critically-acclaimed regional hits as Schoolhouse Rock Live!, Xanadu, Sisters of Swing: The Story of The Andrews Sisters, and Shout! The Mod Musical, comes a brand new musical that celebrates America's favorite pastime: Game Shows!

\section{About The Show}

Night after night in the 1950 s and 60 s, network game shows kept Americans glued to their seats - and their TV sets! - waiting to see who would become the next BIG WINNER! It's time we bring this enchanting time in American pop-culture history to the stage.

With original music, a witty (scandal-filled!) script, audience participation, unpredictable contestants, and fabulous prizes, our new show will bring the game show world to life in this world premier on The Retro Dome stage.

THANKS FOR PLAYING: THE GAME SHOW SHOW! is being developed with a professional cast of actors and will have audience participation, prizes, and of course, sensational music. The script is a celebration of the changing role of the female in American society during the ' 50 s and ' 60 s and showcases how television changed the world we live in. And of course, we'll see a scandal erupt as we explore the world of Quiz Shows and Game Shows!

Our Goal

We will produce the production in San Jose before sending the show to New York for a limited run, creating an Original Cast Recording, and packaging the production for other companies to license. To make this happen we need to raise approximately $\$ 100,000$ BUT we're kick starting our campaign with an "ask" of $\$ 50,000$.

If 500 fans give just $\$ 100$, we'll reach our goal! Check out the great rewards we'll offer for supporting our campaign listed. If you are already planning to attend the performance, a $\$ 100$ gift rewards you with not only a ticket for admission but other
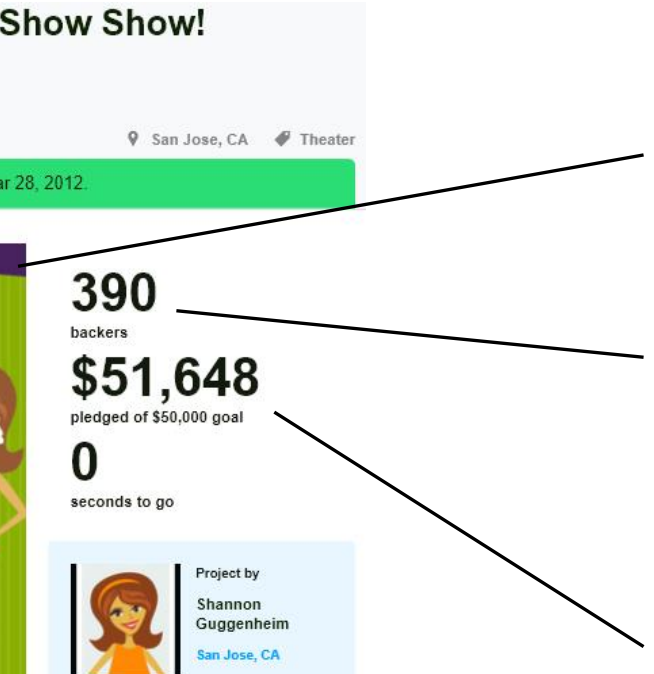

K 2 created 6 backed

If Shannon Miner Guggenheim 89 friends

(6) themeshuganutcracker.com \begin{tabular}{l|l}
\hline See full bio & Contact me
\end{tabular}

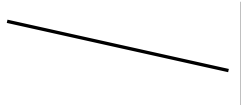

Project creator

Number of people backing the project

Project goal and amount raised. Project creators do not get any money until the goal is reached.

Pledge $\$ 10$ or more

17 backers

THE STUDIO AUDIENCE: For you pledge, you'll receive our sincere thanks and your name will

Estimated delivery: Apr 2012

Pledge $\mathbf{S 1 8}$ or more

07 backers

CONTESTANT ROW: The above PLUS an MP 3 of our theme song

Estimated delivery: Apr 2012

Pledge $\$ 25$ or more

O. 47 backers

CHALLENGER The above, PLUS special recognition in the Playbill AND a free popcorn

Estimated delivery: May 2012

Pledge $\mathbf{\$} 36$ or more

9 backers

RETURNING CHAMPION: Th above, PLUS a limited edition, collectible show poster autographed by the show's creators.

Estimated delivery: May 201

Pledge $\mathbf{\$ 5 0}$ or more

Q 40 backers

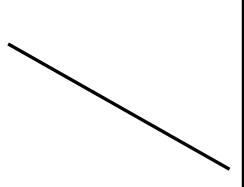

Rewards offered in return for backing the project. Tickets for the project itself were not available until the \$100 reward level.

LOVELY ASSISTANT: The above,

PLUS a customized Water Bottle with

the show brand imprint with free refills 
Figure 2: Kernel Density plots of average scores assigned to projects by experts

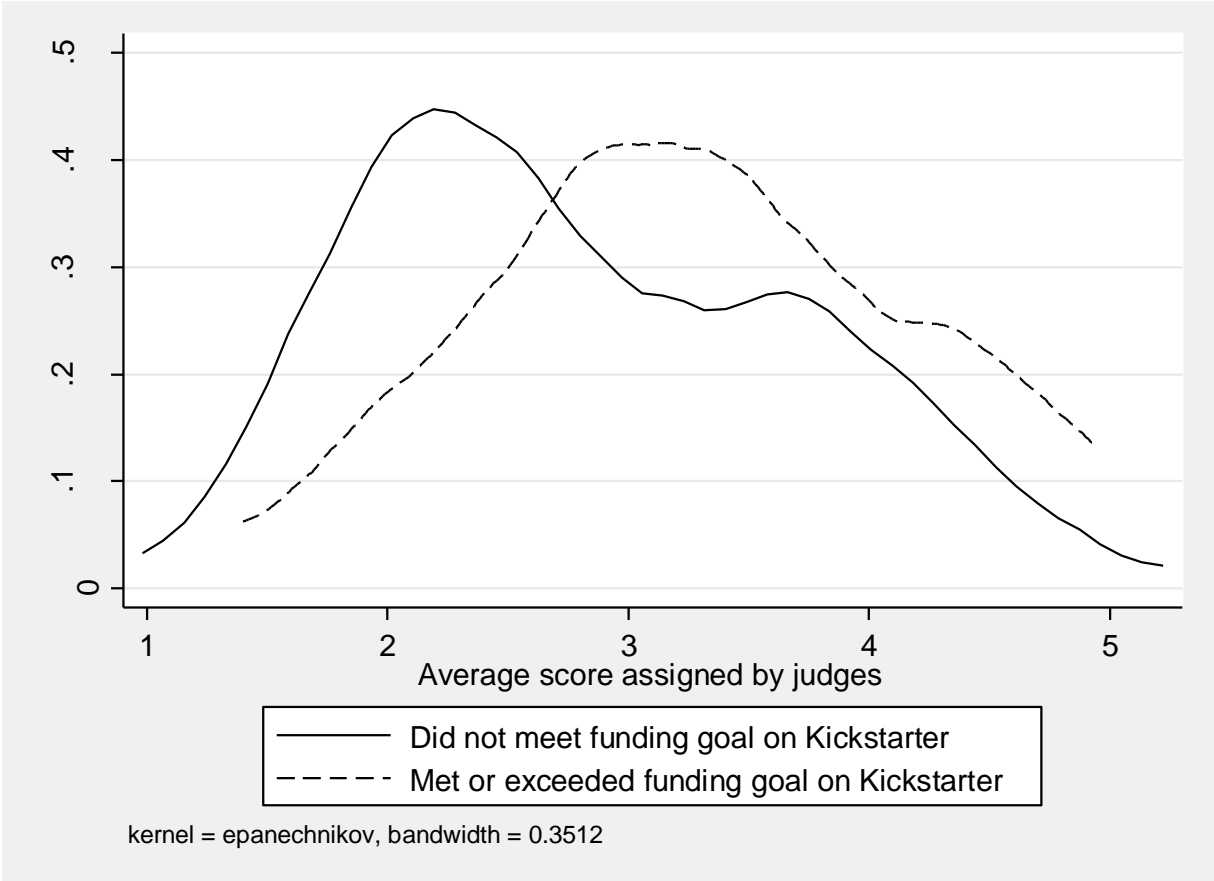

Figure 3: Kernel Density plots of average funding amounts

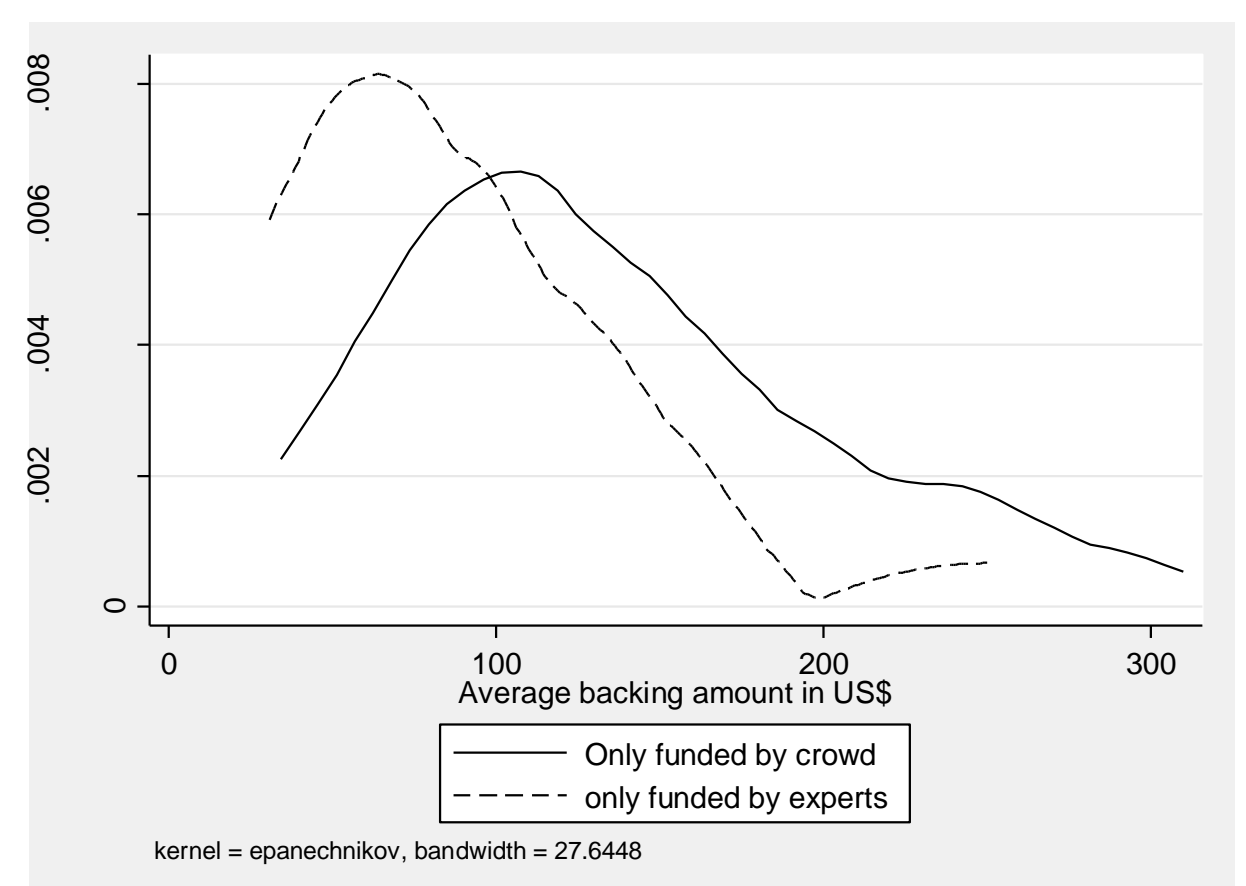




\section{Table 1}

\section{Descriptive Statistics on Projects}

\begin{tabular}{|c|c|c|c|c|}
\hline & All & $\begin{array}{l}\text { Reached or } \\
\text { exceeded } \\
\text { funding goal } \\
\text { on } \\
\text { Kickstarter }\end{array}$ & $\begin{array}{c}\text { Did not } \\
\text { reach } \\
\text { funding goal } \\
\text { on } \\
\text { Kickstarter }\end{array}$ & $\begin{array}{l}\text { T-test for } \\
\text { difference }\end{array}$ \\
\hline Number of projects & 120 & 60 & 60 & \\
\hline Number of evaluations from judges & 180 & 90 & 90 & \\
\hline Probability judge was familiar with project & $6.1 \%$ & $7.7 \%$ & $4.4 \%$ & 0.35 \\
\hline Average Score & 3.0 & 3.1 & 2.8 & $0.01 * * *$ \\
\hline Average Novelty & 2.8 & 3.0 & 2.6 & $0.02 * *$ \\
\hline Average Relevance & 2.7 & 2.9 & 2.6 & $0.04 * *$ \\
\hline Average Quality & 3.0 & 3.2 & 2.7 & $<0.01 * * *$ \\
\hline Average Feasibility & 3.4 & 3.6 & 3.2 & $<0.01 * * *$ \\
\hline Average Reach & 2.8 & 2.9 & 2.7 & $0.09 *$ \\
\hline $\begin{array}{l}\text { Probability ranked as "Best" among set of } \\
\text { projects evaluated } \\
\text { Probability ranked as "Worst" among set of } \\
\text { projects evaluated }\end{array}$ & $\begin{array}{l}17 \% \\
17 \%\end{array}$ & $22 \%$ & $11 \%$ & $\begin{aligned} & 0.05^{* *} \\
< & 0.01 * * *\end{aligned}$ \\
\hline Average funding share proposed by judges & $44 \%$ & $52 \%$ & $35 \%$ & $<0.01 * * *$ \\
\hline
\end{tabular}


Table 2

Correlation between judge evaluations and Kickstarter success

\begin{tabular}{lccccccccc}
\hline \multicolumn{1}{c}{ DEPENDENT VARIABLES } & \multicolumn{3}{c}{ Average Score from judges } & & \multicolumn{3}{c}{ Funding share proposed by } \\
judges
\end{tabular}

Notes: This table reports the results of OLS regressions, where the dependent variable is either the average score that the judge assigned a project or the share of funding goal that the judge proposed the project should get. Specifications (2), (3), (5) and (6) control for the background of the judges, including the number of times they have evaluated grant applications for theatre projects, their affiliation with the theatre industry, their familiarity with specific projects and the time they took to complete the survey. Columns (3) and (6) further add individual fixed effects for each judge. The key coefficients of interest are related to indicator variables for whether the project either reached or exceeded its goal on Kickstarter. These coefficients are estimated relative to the category of projects that did not reach their goal on Kickstarter. We report robust standard errors that are clustered by judge. ${ }^{*}, * *$ and $* * *$ refer to significance at $10 \%, 5 \%$ and $1 \%$ respectively. 
Table 3a

\section{Level of Agreement between Crowds and Experts}

\begin{tabular}{|c|c|c|c|c|c|c|}
\hline & \multicolumn{2}{|c|}{ Funding threshold is $100 \%$ of goal } & \multicolumn{2}{|c|}{ Funding threshold is $75 \%$ of goal } & \multicolumn{2}{|c|}{ Funding threshold is $50 \%$ of goal } \\
\hline & (1) & $(2)$ & (3) & (4) & (5) & (6) \\
\hline & $\begin{array}{l}\text { Share of cases where } \\
\text { Experts and Crowd } \\
\text { agree on funding } \\
\text { outcome }\end{array}$ & $\begin{array}{c}\text { Share of } \\
\text { disagreement cases } \\
\text { where crowd funds } \\
\text { but experts do not }\end{array}$ & $\begin{array}{l}\text { Share of cases where } \\
\text { Experts and Crowd } \\
\text { agree on funding } \\
\text { outcome }\end{array}$ & $\begin{array}{l}\text { Share of } \\
\text { disagreement cases } \\
\text { where crowd funds } \\
\text { but experts do not }\end{array}$ & $\begin{array}{l}\text { Share of cases } \\
\text { where Experts and } \\
\text { Crowd agree on } \\
\text { funding outcome }\end{array}$ & $\begin{array}{c}\text { Share of } \\
\text { disagreement cases } \\
\text { where crowd funds } \\
\text { but experts do not }\end{array}$ \\
\hline Mean & $58.8 \%$ & $80 \%$ & $58.8 \%$ & $76 \%$ & $62.1 \%$ & $57 \%$ \\
\hline Minimum & $56.7 \%$ & $71 \%$ & $56.7 \%$ & $68 \%$ & $59.2 \%$ & $44 \%$ \\
\hline 25th percentile & $57.9 \%$ & $78 \%$ & $57.9 \%$ & $74 \%$ & $60.8 \%$ & $52 \%$ \\
\hline Median & $58.8 \%$ & $80 \%$ & $58.8 \%$ & $76 \%$ & $62.1 \%$ & $57 \%$ \\
\hline 75th percentile & $59.6 \%$ & $82 \%$ & $59.6 \%$ & $78 \%$ & $63.3 \%$ & $58 \%$ \\
\hline Maximum & $60.8 \%$ & $89 \%$ & $60.8 \%$ & $84 \%$ & $65.0 \%$ & $68 \%$ \\
\hline
\end{tabular}

Notes: This table reports the degree to which experts and crowds agree on which projects to fund, and the extent to which the disagreement is driven by projects funded by the crowd and not experts versus those funded by experts but not the crowd. We create three funding thresholds for experts $(100 \%, 75 \%$ and $50 \%)$ so that a project is deemed funded by an expert only if they allocated more than that threshold for the given project. We then look at all 1,024 possible combinations of judges and for each combination, calculate the extent to which the experts would have agreed with the crowd's funding decision, given the different funding thresholds. Columns (1), (3) and (5) report the degree of agreement between experts and crowds and different percentiles of the distribution across the 1,024 combination of judges. For example, the average degree of agreement at the $75 \%$ funding threshold was $58.8 \%$. Columns (2), (4) and (6) further report the extent to which the disagreement is driven by crowds funding the projects the experts would have rejected or vice-versa. They show that most of the disagreement is comprised of projects funded by the crowd but rejected by the experts. For example, $76 \%$ of the projects where experts and crowds did not agree at the $75 \%$ funding threshold were ones where the crowd funded the project but experts did not. Hence, only $24 \%$ of the disagreements in this example were due to projects funded by experts but rejected by the crowd. 
Table 3b

\section{Level of Agreement between Crowds and Experts}

\begin{tabular}{|c|c|c|c|c|c|c|}
\hline \multirow[t]{2}{*}{ DEPENDENT VARIABLES } & \multicolumn{2}{|c|}{$\begin{array}{l}\text { Funding threshold is } 100 \% \text { of } \\
\text { goal }\end{array}$} & \multicolumn{2}{|c|}{$\begin{array}{c}\text { Funding threshold is } 75 \% \text { of } \\
\text { goal }\end{array}$} & \multicolumn{2}{|c|}{ Funding threshold is $50 \%$ of goa } \\
\hline & (1) & (2) & (3) & (4) & (5) & (6) \\
\hline \multirow[t]{2}{*}{ Reached or Exceeded goal on Kickstarter } & $0.167^{* *}$ & $0.167 * *$ & $0.183^{* *}$ & $0.183^{* *}$ & $0.250 * * *$ & $0.250^{* *}$ \\
\hline & $(0.073)$ & $(0.077)$ & $(0.073)$ & $(0.077)$ & $(0.083)$ & $(0.087)$ \\
\hline \multirow[t]{2}{*}{ Constant } & 0.108 & $0.167^{* * *}$ & 0.138 & $0.183^{* * *}$ & $0.218^{*}$ & $0.317^{* * *}$ \\
\hline & $(0.077)$ & $(0.039)$ & $(0.095)$ & (0.039) & $(0.110)$ & $(0.044)$ \\
\hline Controls & Yes & Yes & Yes & Yes & Yes & Yes \\
\hline Judge fixed effects & No & Yes & No & Yes & No & Yes \\
\hline Number of observations & 120 & 120 & 120 & 120 & 120 & 120 \\
\hline R-squared & 0.1 & 0.19 & 0.13 & 0.29 & 0.12 & 0.27 \\
\hline
\end{tabular}

Notes: This table reports the results of OLS regressions, where the dependent variable is an indicator variable that takes the value of 1 if the crowds and experts agree on the funding decision. Columns 1-2 run specifications where the expert is deemed to have funded the project when the funding threshold is $100 \%$, columns $3-4$ refer to the funding threshold of $75 \%$ and columns $5-6$ refer to the funding threshold of $50 \%$. The key coefficient of interest is an indicator variables for whether the project either reached or exceeded its goal on Kickstarter. These coefficients are estimated relative to the category of projects that did not reach their goal on Kickstarter. We report robust standard errors that are clustered by judge. ${ }^{*}, * *$ and ${ }^{* * *}$ refer to significance at $10 \%, 5 \%$ and $1 \%$ respectively. 


\section{Table 4}

Differences in the characteristics of projects funded by judges and crowds

\begin{tabular}{|c|c|c|c|c|c|c|c|c|c|}
\hline DEPENDENT VARIABLES & Log of goal & $\begin{array}{c}\text { Average } \\
\text { investment size }\end{array}$ & Reward levels & $\begin{array}{c}\text { Number of } \\
\text { updates }\end{array}$ & $\begin{array}{l}\text { Number of } \\
\text { pictures }\end{array}$ & $\begin{array}{c}\text { Number of } \\
\text { videos }\end{array}$ & $\begin{array}{l}\text { Formal } \\
\text { Language }\end{array}$ & $\begin{array}{l}\text { Log number of } \\
\text { Facebook } \\
\text { friends }\end{array}$ & $\begin{array}{l}\text { Located in NY } \\
\quad \text { or CA }\end{array}$ \\
\hline & (1) & (2) & (3) & (4) & (5) & (6) & (7) & (8) & (9) \\
\hline \multirow[t]{2}{*}{ (a) Funded by both } & -0.185 & $24.911^{*}$ & 1.358 & $5.003 * * *$ & -0.002 & -0.032 & -0.654 & 0.735 & -0.103 \\
\hline & (0.148) & (13.649) & (1.116) & (1.853) & (0.101) & $(0.078)$ & (1.133) & (0.874) & $(0.126)$ \\
\hline \multirow[t]{2}{*}{ (b) Only experts } & $-0.410 *$ & -12.623 & $-1.096 *$ & -0.588 & $-0.184 * * *$ & $-0.122^{* *}$ & 2.636 & -0.047 & -0.148 \\
\hline & $(0.220)$ & (13.870) & (0.573) & $(0.780)$ & $(0.056)$ & $(0.048)$ & (1.737) & (1.096) & $(0.167)$ \\
\hline \multirow[t]{2}{*}{ (c) Only crowd } & $-0.239 * *$ & $49.755^{* * *}$ & $1.738^{* *}$ & $3.065^{* * *}$ & 0.053 & 0.062 & -0.330 & 0.399 & 0.148 \\
\hline & $(0.120)$ & (12.898) & $(0.860)$ & $(1.002)$ & $(0.090)$ & $(0.080)$ & (0.992) & $(0.682)$ & $(0.090)$ \\
\hline \multirow[t]{2}{*}{ Constant } & $9.866 * * *$ & $84.747^{* * *}$ & $8.551^{* * *}$ & $2.224 * * *$ & $0.184 * * *$ & $0.122^{* *}$ & $25.284^{* * *}$ & $2.394 * * *$ & $0.694 * * *$ \\
\hline & $(0.089)$ & $(7.900)$ & $(0.487)$ & $(0.574)$ & $(0.056)$ & $(0.048)$ & $(0.657)$ & $(0.444)$ & $(0.067)$ \\
\hline $\mathrm{p}$ value for the difference between (b) and (c) & 0.42 & $<0.01^{* * *}$ & $0.06^{*}$ & $<0.01 * * *$ & $0.01 * *$ & $0.01 * *$ & $0.09 *$ & 0.76 & 0.14 \\
\hline Controls & Yes & Yes & Yes & Yes & Yes & Yes & Yes & Yes & Yes \\
\hline Judge fixed effects & Yes & Yes & Yes & Yes & Yes & Yes & Yes & Yes & Yes \\
\hline Number of observations & 120 & 120 & 120 & 120 & 120 & 120 & 120 & 120 & 120 \\
\hline R-squared & 0.057 & 0.146 & 0.053 & 0.189 & 0.060 & 0.029 & 0.007 & 0.007 & 0.065 \\
\hline
\end{tabular}

Notes: This table reports the results of OLS regressions, where the dependent variables refer to a number of characteristics of the projects. Each of the 120 projects is divided into one of four categories (1) those that were funded by the crowd and were deemed good enough to receive at least $75 \%$ of their funding goal by experts (2) those that were given at least $75 \%$ of their funding goal by experts but not funded by the crowd (c) those that the crowd funded but were not highly funded by experts and (d) those that did not reach their goal either from the crowd or experts. The first three coefficients a re estimated relative to the fourth category. We report robust standard errors that are clustered by judge and *,** and *** refer to significance at the $10 \%, 5 \%$ and $1 \%$ respectively. 
Table 5

Evaluation of projects funded by judges and crowds

\begin{tabular}{|c|c|c|c|c|c|c|}
\hline DEPENDENT VARIABLES & Combined average score & Novelty & Relevance & Quality & Feasibility & Commercial viability \\
\hline & (1) & $(2)$ & (3) & $(4)$ & $(5)$ & (6) \\
\hline \multirow[t]{2}{*}{ Funded by both } & $1.557 * * *$ & $1.587 * * *$ & $1.729 * * *$ & $1.864 * * *$ & $1.350 * * *$ & $1.252 * * *$ \\
\hline & $(0.202)$ & $(0.278)$ & $(0.263)$ & $(0.301)$ & $(0.189)$ & $(0.260)$ \\
\hline \multirow[t]{2}{*}{ Only experts } & $1.024 * * *$ & $1.005^{* * *}$ & $0.964 * * *$ & $1.342^{* * *}$ & $0.751^{* * *}$ & $1.052 * * *$ \\
\hline & $(0.187)$ & $(0.284)$ & $(0.295)$ & $(0.225)$ & $(0.249)$ & $(0.235)$ \\
\hline \multirow[t]{2}{*}{ Only crowd } & 0.309 & 0.266 & 0.306 & $0.436^{*}$ & 0.216 & 0.312 \\
\hline & $(0.209)$ & $(0.220)$ & $(0.248)$ & $(0.225)$ & $(0.246)$ & $(0.270)$ \\
\hline \multirow[t]{2}{*}{ Constant } & $2.271^{* * *}$ & $1.369 * * *$ & $1.777^{* * *}$ & $2.155^{* * *}$ & $3.481^{* * *}$ & $2.576 * * *$ \\
\hline & (0.089) & $(0.100)$ & $(0.103)$ & $(0.112)$ & $(0.102)$ & $(0.115)$ \\
\hline Number of observations & 120 & 120 & 120 & 120 & 120 & 120 \\
\hline R-squared & 0.58 & 0.53 & 0.55 & 0.52 & 0.47 & 0.41 \\
\hline
\end{tabular}

Notes: This table reports the results of OLS regressions, where the dependent variable is either the average score that the judge assigned a project along a range of different dimensions. All specifications include individual judge fixed effects and controls outlined in Table 2. Each of the 120 projects is divided into one of four categories (1) those that were funded by the crowd and were deemed good enough to receive at least 75\% of their funding goal by experts (2) those that were given at least $75 \%$ of their funding goal by experts but not funded by the crowd (c) those that the crowd funded but were not highly funded by experts and (d) those that did not reach their goal either from the crowd or experts. The first three coefficients are estimated relative to the fourth category. We report robust standard errors that are clustered by judge and $*, * *$ and $* * *$ refer to significance at the $10 \%, 5 \%$ and $1 \%$ respectively. 


\section{Table 6}

\section{Outcome of projects Funded by Experts and Crowds}

\begin{tabular}{|c|c|c|c|c|}
\hline Classification & Project Type & $\begin{array}{l}\text { Ranked best among } 6 \\
\text { projects by (most } \\
\text { favorable) judge? }\end{array}$ & Commercial outcome & Critical outcome \\
\hline Success & Bringing play to festival & Yes & $\begin{array}{l}\text { Several small sold out shows at the festival. Two offers for tours } \\
\text { afterward }\end{array}$ & $\begin{array}{l}\text { Mixed reviews in national } \\
\text { press. }\end{array}$ \\
\hline Success & $\begin{array}{l}\text { Extending run of one } \\
\text { woman play }\end{array}$ & Yes & Sold out 10 shows at 60 seats each show & $\begin{array}{l}\text { Mixed reviews in national } \\
\text { press. }\end{array}$ \\
\hline Success & $\begin{array}{l}\text { Launching a pop-up } \\
\text { theater company with an } \\
\text { original play }\end{array}$ & Yes & $\begin{array}{l}\text { Launched a new theater company with a new play with over } \\
90 \% \text { of the seats filled. Sold } 314 \text { tickets, made a profit of over } \\
\$ 4,000 \text {. }\end{array}$ & Positive local press. \\
\hline Success & $\begin{array}{l}\text { Play featuring shelter } \\
\text { dogs }\end{array}$ & Yes & Ran for one month. Broke even. & $\begin{array}{l}\text { Covered but not reviewed } \\
\text { by national and local } \\
\text { press. }\end{array}$ \\
\hline Success & Original musical & No & $\begin{array}{l}\text { Ran for one month, sold } 600 \text { seats, with a profit of about } \\
\$ 15,000 \text {, "significantly below expectations" }\end{array}$ & $\begin{array}{l}\text { Positively covered in local } \\
\text { press, no review. }\end{array}$ \\
\hline Success & Original play & No & Ran for one month, 2,660 tickets sold, profit of $\$ 45,000$ & $\begin{array}{l}\text { Positive reviews in local } \\
\text { press. }\end{array}$ \\
\hline Success & $\begin{array}{l}\text { Revival of Tony award- } \\
\text { winning play }\end{array}$ & No & $\begin{array}{l}3 \text { week run in New York. } 12 \text { shows in a } 50 \text { seat theater. The last } \\
\text { three were sold out, the shows prior were about half to two } \\
\text { thirds full. }\end{array}$ & $\begin{array}{l}\text { No official coverage in } \\
\text { publications }\end{array}$ \\
\hline Success & Interpretation of Hamlet & No & Toured for one year through various theaters & $\begin{array}{l}\text { Mixed reviews in national } \\
\text { press. }\end{array}$ \\
\hline Success & Original musical & No & 7 sold out performances in 100 person theater. Broke even. & $\begin{array}{l}\text { Negative to mixed } \\
\text { reviews in national press. }\end{array}$ \\
\hline
\end{tabular}




\begin{tabular}{|c|c|c|c|c|}
\hline Success & Original musical & No & Ran for two days, sold 300 tickets, profit of $\$ 1,500$ & $\begin{array}{l}\text { No reviews, though the } \\
\text { play was mentioned in } \\
\text { national press. }\end{array}$ \\
\hline $\begin{array}{l}\text { Commercial } \\
\text { Hit }\end{array}$ & $\begin{array}{l}\text { Original musical with } \\
\text { social message }\end{array}$ & Yes & $\begin{array}{l}\text { Ongoing profitable performances, touring continuously. } \\
\text { Secured underwriting after campaign. Makes } \$ 200,000 \mathrm{~K} \text { per } \\
\text { year in net revenue and } \$ 100,000 \mathrm{~K} \text { in underwriting and is self- } \\
\text { supporting }\end{array}$ & $\begin{array}{l}\text { No reviews, though } \\
\text { coverage in many national } \\
\text { publications. }\end{array}$ \\
\hline
\end{tabular}




\section{Table 7}

\section{Outcome of projects rejected by experts but funded by crowds}

\begin{tabular}{|c|c|c|c|c|}
\hline Classification & Project Type & $\begin{array}{l}\text { Ranked worst } \\
\text { among by (most } \\
\text { favorable) judge? }\end{array}$ & Commercial outcome & Critical outcome \\
\hline Failure & Brecht play & No & Ran for 4 days in New York, run cut short. & "Negative local reviews. \\
\hline Success & $\begin{array}{l}\text { Original } \\
\text { comedy } \\
\text { show }\end{array}$ & No & $\begin{array}{l}\text { Two shows in New York with a total of } 130 \text { people. They were hoping } \\
\text { to raise additional funding, but failed. }\end{array}$ & No official coverage in publications \\
\hline Success & $\begin{array}{l}\text { Original } \\
\text { musical for } \\
\text { children }\end{array}$ & Yes & $\begin{array}{l}\text { Show ran for two weeks in New York, with 2,000 audience members. } \\
\text { Licensed productions currently running in four states }\end{array}$ & No official coverage in publications \\
\hline Success & $\begin{array}{l}\text { Production } \\
\text { of Macbeth }\end{array}$ & Yes & Show ran in local market, 250 people attended & No official coverage in publications \\
\hline Success & Original play & Yes & Four performances at fringe festival. $\$ 1,000$ in ticket sales & Covered in local news, no review. \\
\hline Success & $\begin{array}{l}\text { Concert } \\
\text { staging of a } \\
\text { Broadway } \\
\text { play }\end{array}$ & No & Show ran for three performances at capacity, 600 audience members & No official coverage in publications \\
\hline Success & $\begin{array}{l}\text { Musical on a } \\
\text { boat }\end{array}$ & No & $\begin{array}{l}10 \text { performances in New York. Raising funding for additional } \\
\text { performances }\end{array}$ & No official coverage in publications \\
\hline Success & Original play & No & $\begin{array}{l}5 \text { performances in New York. } 60 \% \text { full on average ( } 75 \text { seats per } \\
\text { performance) }\end{array}$ & No official coverage in publications \\
\hline Success & Original play & No & $\begin{array}{l}1 \text { month run. } \$ 17,055.64 \text { gross revenue in ticket sales, merchandise and } \\
\text { concessions. Hoped to create a touring show, but still working on } \\
\text { funding. }\end{array}$ & Mixed reviews in local press. \\
\hline Success & $\begin{array}{l}\text { Staging of } \\
\text { Tennessee } \\
\text { Williams Play }\end{array}$ & No & Ran for two weeks in local market, 250 audience members & Positive local reviews. \\
\hline Success & Original play & No & $\begin{array}{l}\text { Show ran for one month Off-Off Broadway in New York. Made } \$ 24,000 \\
\text { in revenue. }\end{array}$ & Positive local reviews. \\
\hline
\end{tabular}




\begin{tabular}{|c|c|c|c|c|}
\hline Success & Original play & No & $\begin{array}{l}\text { Toured various theaters. } 1200-1500 \text { audience members total. Broke } \\
\text { even. Additional tours planned. }\end{array}$ & Positive local reviews. \\
\hline Success & $\begin{array}{l}\text { Original anti- } \\
\text { bullying play } \\
\text { for children }\end{array}$ & No & $\begin{array}{l}\text { Continual performances in New York, over } 12,000 \text { children total in } \\
\text { audience }\end{array}$ & No official coverage in publications \\
\hline Artistic Hit & Original play & No & $\begin{array}{l}\text { Show ran for two weeks Off-Off Broadway in New York. Made } \$ 2,500 \text { in } \\
\text { ticket sales }\end{array}$ & $\begin{array}{l}\text { Was nominated for two New York Innovative Theatre } \\
\text { Awards and won one. Positive local reviews. }\end{array}$ \\
\hline Artistic Hit & Original play & No & $\begin{array}{l}1 \text { month in New York, nearly sold out. } \$ 20,000 \text { in ticket sales. Play being } \\
\text { published as a book }\end{array}$ & $\begin{array}{l}\text { Extremely positive local and national reviews. Reviews } \\
\text { were most positive of any play in the study. }\end{array}$ \\
\hline $\begin{array}{l}\text { Commercial } \\
\text { Hit }\end{array}$ & $\begin{array}{l}\text { Original } \\
\text { musical }\end{array}$ & No & $\begin{array}{l}5 \text { sold out performances in New York, audience of 1,100. Gained an off- } \\
\text { Broadway run for over } 2 \text { months. }\end{array}$ & Mixed to positive reviews in local and national press. \\
\hline $\begin{array}{l}\text { Commercial } \\
\text { Hit }\end{array}$ & $\begin{array}{l}\text { Original } \\
\text { musical }\end{array}$ & No & $\begin{array}{l}\text { Ran for } 4 \text { months. } 300 \text { seat theatre; four show a week; } 12 \text { weeks; } \\
\text { general } 2 / 3 \text { full to full houses }\end{array}$ & $\begin{array}{l}\text { Winner of Best Local Musical and four other awards. } \\
\text { Generally positive reviews. }\end{array}$ \\
\hline
\end{tabular}




\section{Appendix : Survey Procedure and Questions}

Judges were contacted from among the list of experts who had previously acted as judges for major theater competitions and grants (the National Endowment for the Arts, Drama Desk Awards, New York Drama Critics' Circle, Pulitzer Prize for Drama, Theatre World Award, and Tony Awards).

Judges were electronically asked to score six projects using the criteria below. All questions asked on a 1-5 point Likert scale, with 1 being "strongly disagree" and 5 being "strongly agree"

\section{Novelty}

This project displays a high degree of artistic ingenuity

Assuming it was completed as planned, this project would advance the art form

This project is original

\section{Quality}

The proposal for the project is of high quality

The video added to the proposal in a meaningful way

The artistic vision of the proposal is clear

\section{Feasibility/Realism}

The artistic and/or commercial goals of this project are achievable

The individual or group proposing this project are qualified to complete the project

This project can be implemented with the resources in the proposal

\section{Stakeholders and Reach}

This project would reach a diverse audience

This project would attract a wide range of potential funders and stakeholders

This project would be commercially viable/profitable

\section{Relevance}

Assuming it was completed as planned, this project would advance a cultural, political, or artistic dialogue

This project promotes a high sense of audience engagement

I feel personally excited about this project 